\title{
LA RETÓRICA EPISTOLAR (1803), DE ANTONIO MARQUÉS Y ESPEJO, COMO MÉTODO PARA FACILITAR LA COMUNICACIÓN ESCRITA EN UNA SOCIEDAD MODERNA
}

\author{
The Retórica epistolar (1803), by Antonio Marqués \\ y Espejo, as a Method to Facilitate Written Communication \\ in a Modern Society
}

Felipe RODRÍGUEZ MORÍN

Instituto Feijoo de Estudios del Siglo XVIII

felipe.rodriguezmorin@asturias.org

Fecha de recepción: 26/09/2018

Fecha de aceptación definitiva: 11/04/2019

RESUMEN: Se deja constancia en este trabajo de cómo ante las nuevas necesidades de una sociedad más ilustrada y burguesa, que hizo de la carta un vehículo de uso frecuente como medio de relación entre las personas, Marqués y Espejo, siempre al quite en cuanto a la captación de lectores, aprovechó dicha circunstancia para publicar su libro, Retórica epistolar -una traducción, casi en su totalidad, de una obra francesa-, con el fin de allanar así las dificultades que muchos de los emisores de este tipo de escritos solían tener a la hora de redactarlos. Tampoco dejó de lado Marqués en este tratado su sempiterna ambición de mejora para las mujeres, plasmando al final de su volumen una serie de misivas, originales suyas, en las que se aportan algunas claves acerca de su ideal en cuanto a la educación de las jóvenes.

Palabras clave: Retórica epistolar; manuales epistolares modernos; tipos de cartas misivas; Philipon de la Madelaine; Le secrétaire parfait; educación femenina. 
ABSTRACT: This study establishes Marqués y Espejo's Retórica epistolar as a text that is almost entirely a translation from a French work. Marqués y Espejo recognized the fact that the more learned, bourgeois society of the time often used letters to communicate. Always attentive to expanding his readership, Marqués y Espejo adapted his French source to address the difficulties that many letter writers encountered in Spain. Moreover, by including at the end of his treatise a set of original letters penned by himself, Marqués y Espejo reveals his ever-present commitment to improve the situation of women and their education.

Key words: Epistolary Rhetoric; modern epistolary manuals; letter typology; Philipon de la Madelaine; Le secrétaire parfait; female education.

\section{Algunas Cuestiones PREVIAS aCerCa DEL LiBro}

Si de todas las obras de Marqués y Espejo podemos decir que el Viaje de un filósofo a Selenópolis es la más citada por los estudiosos ${ }^{1}$, sin duda alguna hemos de afirmar que, a tenor de la cantidad de ocasiones en que fue reeditada (la última vez en 2001), la que mayor acogida tuvo por el público lector fue, con mucho, la Retórica epistolar ${ }^{2}$.

Su aparición tuvo lugar a finales de mayo o principios de junio de $1803^{3}$, fruto de la imprenta madrileña de Cruzado, compuesto de 274 páginas en $8 .^{\circ}$ menor, y con el título completo de Retórica epistolar, o arte nuevo de escribir todo género de cartas misivas y familiares; con ejemplos de los autores más célebres extranjeros y nacionales. Por el doctor D.-, Presbitero, Pensionado por su Majestad. De la gran aceptación de la que gozó nos da cuenta, varios meses después de su lanzamiento, la Gaceta de Madrid (n. ${ }^{\circ}$ 10, de 3 de febrero de 1804, p. 112), poniendo de relieve una paradoja, pues la próspera venta del compendio obligó a una bajada en su precio, a causa de la baja calidad con que se hallaban confeccionados los ejemplares que faltaban por despachar: "No quedando de esta obra más que los ejemplares del papel de surtido o regular, es fuerza innovarla en precio; así será en lo sucesivo el de 11 reales en pasta, 10 en pergamino y 9 a la rústica».

Pero a pesar de ese éxito que acabó cosechando, hemos de significar que no gozó, en cambio, de un buen principio, puesto que una vez salió publicado se

1. Se trata, en realidad, de la traducción de Le voyageur philosophe dans un pais inconnu aux habitants de la terre, de VILLENEUEVE (1761), aunque en «drástica selección operada sobre un original mucho más extenso» (Álvarez de Miranda, 2001: 46).

2. ARADRA (1997: 209) califica la Retórica epistolar como «un curioso manual que gozó de gran aceptación en su tiempo».

3. El Diario de Madrid de 1 de junio de 1803 (n. ${ }^{\circ}$ 252: 609) informaba de su precio, a 11 reales en rústica, y de su venta, además de en el establecimiento de Gómez Fuentenebro, «en la librería nueva", sita en el n. ${ }^{\circ} 8$ de la calle de Jacometrezo, que luego pasaría a llamarse de Espejo, y que la Gaceta de Madrid llegó a denominar en alguna ocasión como librería de "Marqués y Espejo" (como, por ejemplo, hizo el 18 de diciembre de 1804, n. ${ }^{\circ}$ 101: 1131, o el de 8 de enero de 1805 , n. ${ }^{\circ}$ 3: 32). 
enfrentó a un problema con el Consejo de Castilla, que, a la sazón, incoó las siguientes actuaciones: "Expediente formado con motivo de [no] haberse entregado al Señor gobernador del Consejo un ejemplar de un libro publicado en la Gaceta ${ }^{4}$ con el título de Retórica Epistolar o arte nuevo de escribir cartas».

Continuando con los trámites administrativos iniciados, el gobernador del Consejo, por medio de una "Nota» fechada el 27 de junio de 1803, hizo presente «la necesidad de tomar providencia que sirva de escarmiento a los autores y libreros, y para contener los abusos y fraudes que en esto se experimentan, y las quejas de los censores por no dárseles el ejemplar que, como tales, les corresponde»5. Consecuencia de lo cual, resultó el decreto que acto seguido despachó la Sala de Gobierno, a fin de que:

El Escribano de diligencias de la Escribanía de Gobierno practique las correspondientes para averiguar quién es el autor del libro que se expresa en la nota antecedente, y el Librero que le vende; y verificado, les haga saber presenten inmediatamente en la Escribanía de Gobierno el libro original, la licencia que tenga para su impresión y los ejemplares necesarios, como está mandado, embargando todo el resto de la impresión a disposición de S. E. el Sr. Gobernador ${ }^{6}$.

En cumplimento de lo dispuesto en el anterior decreto, el 28 de junio, se personó en la librería de Ramón Gómez Fuentenebro7, de la calle Carretas, donde se expendía el libro, el escribano de S. M., y requirió a aquel para que le exhibiese la licencia de publicación y venta, así como para que le manifestase quién lo había escrito. Y así es que «dijo que el citado Libro lo vende por comisión de Don Josef Marqués y Espejo, quien juzga habrá puesto el original con los ejemplares prevenidos en la Escribanía de Gobierno del Consejo». Tras dicha manifestación el fedatario público embargó «en el mismo Ramón Gómez Fuentenebro todos los ejemplares

4. El ejemplar de la aludida Gaceta de Madrid era el correspondiente al 17 de junio de 1803 (n. ${ }^{\circ}$ 48: 512), donde se daba cuenta de la existencia del texto de Marqués; aunque, como ya precisamos, el Diario de Madrid se había anticipado un par de semanas en ese cometido.

5. Archivo Histórico Nacional, en adelante: AHN, Consejos, 5566-12, s. n. Es, por otra parte, la única documentación conservada acerca de este título en el AHN, pues no consta la relativa a la solicitud y aprobación de la licencia de impresión.

6. En cuanto a una posible relajación en estos deberes de los escritores que publicaban sus obras, el referido Consejo parece lanzar una andanada a la institución encabezada por el Juez de imprentas, inmediatamente detrás del párrafo más arriba transcrito: «Sin perjuicio de esto, dígase al Sr. Juez de Imprentas que en las licencias que diere para la impresión de papeles con arreglo a la Real Orden de 19 de Mayo de 1785, o en las obras que para el efecto se le remitan de orden de S. M., cuide se pongan las prevenciones que se usan en las que concede el Consejo: a saber, que se lleve un ejemplar encuadernado en pasta a la Real Biblioteca de S. M. y el original con otros siete (si solo hubiera un censor u ocho si son dos) a la Escribanía de Gobierno para darles el destino que está prevenido; y sin que conste por Certificación de esta haber cumplido el Impresor, no entregue la obra, ni proceda a su venta, pena de ser denunciada».

7. Este establecimiento era propiedad, según afirma MORÁn OrTi (2009: 166), de Manuel de Ribera y Calvillo. 
de dicha obra, sin vender ninguno hasta que otra cosa se mande por el Consejo». Y a continuación: «Incontinenti. Yo, el escribano, hice igual requerimiento y embargo como el de arriba al Librero D. Fernando Marqués y Espejo, hermano del Autor de la obra, en su persona; y enterado, dijo estaba pronto a cumplir con lo mandado».

Más abajo, y al margen de ese folio, existe una "Nota» que da cuenta de la subsanación del defecto advertido por la autoridad: "Se ha entregado en la Escribanía de Gobierno, y por el autor, el original, con la licencia del Sr. Juez de Imprentas, y los siete ejemplares con el recibo de la Biblioteca Real».

Sin perder un instante, el mismo 28 de junio, libró Fernando Marqués un memorial al Consejo solicitando su benevolencia. Y el 1 de julio pasó tal instancia al Consejo de Gobierno, que se mostró magnánimo:

Usando de equidad, se levanta el embargo de la impresión de que se trata, haciéndose saber a este interesado y al otro librero, Ramón Gómez Fuentenebro, que en lo sucesivo se abstengan de vender libro alguno de cualquiera clase que sea, sin que les conste, por recibo o certificación de la Escribanía de Gobierno, haberse entregado en ella los ejemplares correspondientes en la forma que está acordado por punto general, con apercibimiento de que se les impondrán las penas prescritas.

Por último, el cuatro de julio de 1803 el escribano comunicó a los libreros la anterior disposición, y les levantó el embargo.

\section{AlgUNAS CIRCUNSTANCIAS PERSONALES Y SOCIALES EN RELACIÓN CON LA GÉNESIS DE LA OBRA}

Al igual que en otros varios libros de Marqués, en la página que seguía al título apareció estampada la siguiente leyenda a modo de reclamo publicitario: «Este y los demás ejemplares de las obras de su Autor irán firmados y sellados por él mismo». Y acto seguido, colocó Marqués un "Prefacio», compuesto de dos páginas sin numerar, con el fin de presentar su obra; revelando ahí que la misma no había sido compuesta a instancias de nadie, sino que su iniciativa resultaba fruto, únicamente, de su propia experiencia personal, y de sus reflexiones acerca de que el buen o mal uso de la pluma conducía muchas veces al éxito o, por contra, al fracaso de nuestros propósitos. Y resaltaba, en definitiva, que el procurar resultar útil a los demás había sido la pretensión que lo movió a confeccionarla, puesto que hasta entonces se carecía de una herramienta semejante: "Por desgracia, no hallé en la edad en que más la necesitaba obra alguna semejante que supliese a mi falta de experiencia, ni creo la tengamos hasta ahora; por lo mismo me he resuelto a la publicación de esta sin haberla comunicado a nadie».

Aprovechaba también este proemio Marqués para, con las excusas propias del traductor de la época -cosa que en esencia era-, curarse en salud por las probables críticas de sus lectores. Y ello, mediante los conocidos argumentos de no existir un libro igual en España: «Lo hago porque juzgo que puede ser de alguna 
utilidad. Siendo la única en este género, es la mejor», o el de servir de base para que otro, con más talento, mejorase el producto: "Celebrara que, sirviendo ella como de diseño, se dedicase algún literato nuestro a darla toda la extensión de que es capaz». Además, su sempiterno sentido del humor queda patente cuando explícitamente rechazaba otra de las excusas típicas de aquellos traductores que, de pane lucrando, infestaban las prensas con sus desdichadas versiones: "Engañaría yo [al público] si le dijese (como se acostumbra) que los ruegos de algunos eruditos me obligan a darla a luz».

Pero, por más que Antonio Marqués se aplica en reiterar la inexistencia de este género de manuales en castellano, no debemos olvidar que nuestra lengua contaba con unos cuantos libros que versaban sobre la materia; si bien es cierto que muchos de ellos se hallaban anticuados y respondían a necesidades muy distintas a las del lector medio de principios del siglo $\mathrm{XIX}^{8}$. No en vano comenta Castillo Gómez, poniendo precisamente como expreso ejemplo el libro que nos ocupa, que los nuevos manuales de escritura iban ahora destinados a un tipo distinto de lector: "A un público no estrictamente cortesano, sino, en todo caso, letrado, y aún más, burgués. A este propósito es muy ilustrativa la selección de cartas que Antonio Marqués y Espejo introdujo en su Retórica epistolan (2015: 86). Igualmente, Cantos Casenave, haciendo referencia también, entre otras, a la obra que nos ocupa, menciona el hecho de que este género de compendios respondía a "las necesidades del nuevo público burgués en el primer decenio del siglo XIX" (2015: 2).

En consecuencia, quedan desterrados ahora los ornatos y pomposidades de los tiempos pretéritos, pues demandan los nuevos un estilo más práctico y funcional, a través del cual fluyera con gran facilidad la comunicación de contenidos. Por eso, refiriéndose a Mayans (y a la vez a Marqués y Espejo) sintetiza Rueda las cualidades que presidían en esos años este tipo de manuales del modo siguiente: "Como a todo retórico de la época, le enfadan las cartas de prolijo estilo y ensalza las que eligen la brevedad y la sencillez" (2001: 152).

D. y Begas, por su parte, había dado a la estampa, primero en Orihuela y en 1774 en la imprenta de José Doblado de Madrid, que es la edición por nosotros

8. A juicio de García-Godoy el prontuario de Gaspar Ezpeleta y Mallol, aparecido en 1714, Práctica de Secretarios que contiene una concisa [...] distinción de las Cartas misivas [...], se había convertido «en el tratado dieciochesco por excelencia, destinado a la formación de secretarios» (2012: 362). A semejanza del de Marqués, el texto de Ezpeleta incluía unas reglas generales que antecedían a los modelos a imitar e incorporaba también una sección de cartas de amor. Sin embargo, descubría todo él en su conjunto un ambiente ya vetusto y trasnochado, donde, por ejemplo, los hombres paseaban la calle para cortejar a las damas.

En cuanto a este tipo de tratados relacionados con la escritura de cartas, anteriores al de Marqués, EARLE nos facilita una nómina de ellos (2005: 29-30, n.). Asimismo, existe otra, con más de un siglo de antigüedad, proporcionada por DocTOR THEBUSSEN (1891: 567c). 
manejada ${ }^{9}$, el Nuevo estilo y formulario de escribir cartas misivas [...], que resultaba bien cercano a tales potenciales usuarios, y podía ajustarse a sus necesidades. Pero carecía, sin embargo, este método, de la parte teórica que mostraba el libro de Marqués ${ }^{10}$. Por otro lado, los textos allí propuestos como modelos para ser imitados no poseían en absoluto la calidad de los presentados por nuestro autor. A este respecto, no podemos dejar de traer ahora aquí una parte del importante comentario que sobre esta obra de Marqués publicó el Diario Balear de 2 de setiembre de 1819 (n. ${ }^{\circ}$ 244: 3-4), con motivo de la aparición de la segunda edición, y en la que precisamente se ponían en valor las diferencias con otros tratados pretéritos:

Varios eran los libros que teníamos para escribir cartas, con los títulos de Estilos, Secretarios, Prontuarios, pero viendo el autor de esta obra que todos estos solo contenían unas fórmulas inconexas, sin gusto, sin dicción ni oportunidad, se propuso dar una instrucción teórica y práctica de la Retórica epistolar, de que aquellos carecían. Con este objeto formó su nuevo Arte de escribir todo género de Cartas, Esquelas o Billetes y representaciones, en el cual, después de haber dado unas nociones preliminares sobre el estilo epistolar, motivos para escribir cartas, tratamiento y ceremonial que se usa en ellas, presenta modelos de todas, tomados de literatos de nota españoles y extranjeros, precedidos en cada género de las reglas de su formación, y algunas advertencias oportunas, como sobre una cuenta de resaca, obligaciones del tenedor de una letra, sobrescritos, \&c.

Pero, a pesar de estas diferencias, y de que Marqués pudiese reputar el libro de Begas como de distinta naturaleza al suyo, tal vez el conocimiento de su existencia influyera en su ánimo a la hora de asignarle título; pues, de otro modo, sabiendo de su notable talento comercial y de su innata capacidad para la venta, no se alcanza muy bien a ver la razón que lo llevó a escoger uno tan poco atrayente como el de que le acabó endosando: "Retórica epistolar», ininteligible, creemos, para una gran parte del público, y posiblemente disuasorio para quienes tuvieran duda en adquirirlo, pero que lo alejaba en mucha medida no solo del tratado de Begas, sino también de todos los anteriores impresos en España (caso de que

9. Asimismo, sabemos de la existencia de, al menos, otra impresión posterior, ya que el Diario de Madrid de 17 de febrero (n. ${ }^{\circ}$ 48: 194-195) y el Semanario de Salamanca de 12 de julio (n. ${ }^{\circ} 82: 32$ ) saludaban desde sus páginas la edición de 1794.

10. Esta circunstancia no la considera nada baladí MELCHOR DE SAS, pues en su "Introducción" al Arte epistolar [...] (1819: V), aludiendo precisamente a esa falta en el libro de Begas, describía las desventajas que acarreaba dicha omisión a quien fuera a redactar una misiva: "No hallando reglas ningunas teóricas tiene que atenerse únicamente a la práctica de imitar los modelos que les ofrece; y esto no es tan fácil como algunos piensan. Por otra parte, los estilos de escribir cartas, en su fórmula y lenguaje, andando el tiempo varían, y no teniendo algunas reglas por donde poderse dirigir acomódanse a estas variaciones, o tendrán que escribir siempre a la antigua usanza, o, si quieren separarse de la servil imitación, se verán expuestos a cometer mil errores». 
Marqués supiera de ellos), pues en el título de estos no solían faltar expresiones como "estilo", "formulario" o "secretario".

Al hilo de este argumento, podría también explicarse la ausencia de un índice en el libro de Marqués, una falta esta en principio incomprensible e inexcusable, máxime en este género de escritos, puesto que la consulta de aquel podría delatar semejanzas irrefutables con la obra de Begas, ya que en la de este aparece una relación de los tipos de cartas y de sus respuestas, que, nominalmente al menos, resultaría bastante similar a la que hubiese tenido que insertar Marqués.

Por otro lado, para paliar los mencionados inconvenientes del título principal de la obra de D. Antonio, ya venía a echarle un capote el secundario: «arte nuevo de escribir todo género de cartas misivas y familiares", el cual, enunciando claramente la esencia de su contenido, parecía enmendar en mucha parte las menguas del otro. Igualmente, un procedimiento que también resaltaba lo asequible de sus conceptos y los beneficios de su uso era el de los anuncios en los periódicos.

Conforme ya antes dijimos, tanto el Diario de Madrid (1 de junio de 1803, n. ${ }^{\circ}$ 252: 609) como la Gaceta de Madrid (17 de junio, n. $\left.{ }^{\circ} 48: 512\right)$, se hicieron eco de la aparición de este volumen en las librerías; ambos textos, probablemente redactados por el mismo Marqués y Espejo, abundaban en ese aspecto pionero que a él le gustaba recalcar del manual. Así, la primera de dichas publicaciones apuntaba lo siguiente: "Nuestro idioma, tan propio y bello para todos los estilos retóricos, carecía enteramente de un libro en que se reuniesen las reglas de escribir con propiedad", realzando el consiguiente provecho que, de su lectura, se derivaría para la ciudadanía, hasta ahora desprovista de tal recurso, pues: «se fiaba al acaso la dirección de la pluma, motivo por el cual se mantiene nuestro vulgo muy atrasado en este ramo de literatura, tan útil e importante a todo individuo de la sociedad». La Gaceta de Madrid ratificaba, asimismo, esa dimensión de servicio al bien común que propiciaba la lectura "de este arte tan importante a la sociedad, sobre el cual nada tenemos hasta ahora impreso"; y que lo mismo valía para los principiantes: "Guía a los iliteratos con reglas claras y sencillas para que puedan escribir por sí mismos en todo asunto", que para la perfección de los más avezados, ya que "presenta a los instruidos unos ejemplos de Quevedo, Solís, Razin [sic], Fléchier, Sévigné, Vertot, \&c., muy acreedores a la imitación universal» ${ }^{11}$. En este repertorio debemos incluir otros nombres ilustres de la literatura, como Voltaire (cuya identidad enmascara Marqués), o figuras señeras en la redacción de cartas, puesto que, además de la mencionada marquesa de Sévigné, nos encontramos ejemplos de madame de Maintenon, madame de La Fayette, el conde de Bussy, etc.

11. También el Diario de Madrid de 5 de octubre de 1803 (n. ${ }^{\circ}$ 279: 1114) se hace eco de la venta de este título de Marqués, junto "con todas las demás obras del mismo autor", en la misma librería que señalaba el 1 de junio anterior. Asimismo, quedó registrada su existencia en el anuario iniciado en el año 1804 por el propio Marqués en su Almanak literario [...] (1804: 106). 
Entre otros ilustrados que denunciaron el referido y generalizado problema de la falta de instrucción a la hora de componer cartas, podemos traer ahora a colación a Ignacio García Malo, quien, a la par que endilgaba el consiguiente varapalo al sistema educativo, confiaba en que su traslación al castellano de Pamela Andrews podría servir de modelo a la juventud para aprender a escribir cartas, "pues hay muchachos y aun hombres de veinte o veinte y cinco años que, después de haber salido de los Colegios y Universidades, todavía no saben dictar una carta ni contar lo que les pasa con precisión, claridad, facilidad y sencillez». Preguntándose por la razón de ello, emitía la respuesta de inmediato: "Por la falta de lectura de libros de esta especie», y efectuaba, al paso, una observación que puede tener su trascendencia para el libro que estudiamos, ya que aseguraba que "[ese] defecto es mucho más común en la educación de las mujeres» ${ }^{12}$.

Abrimos aquí un paréntesis para recordar que Antonio Marqués y Espejo, nacido en 1762 en Gárgoles de Abajo (Guadalajara), se había ordenado sacerdote en París en abril de 1789, y tras un período de tiempo destinado en la iglesia colegial de Ampudia (Palencia), como profesor de Latín, primero, y luego como canónigo -una etapa esta en la que aun tuvo tiempo para ir a la Guerra de la Convención en calidad de capellán castrense-, llegó a Madrid en 1801, a la edad de 39 años, para ocupar plaza de capellán colector en la Real Casa de Recogidas, institución que se encargaba de acoger a mujeres descarriadas.

En este punto es donde creemos que los objetivos literarios de Marqués, sensibilizado ahora por la situación con la que de continuo convivía, y donde podía observar de primera mano los estragos de una vida licenciosa, dieron un vuelco radical, y se orientaron de modo especial a la formación de las jóvenes, para que, provistas de una educación adecuada, pudieran esquivar los peligros mundanos y afrontar su futuro con unos sólidos principios. Y así es que, durante esos años, se observa en sus trabajos como escritor un afán constante por ilustrar a las damas, y se echa de ver en sus obras, tanto en los contenidos como en los propios títulos de las mismas, un indiscutible protagonismo femenino. De tal intención surgió, por ejemplo, la revista que, bajo el rótulo de Liceo General del Bello Sexo, pretendió publicar en 1804, y que se quedó en un intento vano a causa de la prohibición por parte de las autoridades de los papeles periódicos no oficiales ${ }^{13}$. O también da muestra de ese propósito en el citado Viaje de un filósofo a Selenópolis, mediante la inserción del capítulo VIII, ausente en el original francés: "Biblioteca particular del bello sexo Selenítico", y sobre todo el colosal proyecto que, inicialmente, iba a suponer la Biblioteca selecta de las damas, aunque finalmente únicamente salieron a la luz, entre los años 1806 y 1807, un total de trece volúmenes.

12. Richardson, S. Pamela Andrews. "Prólogo del traductor» (1799, t. I: VII).

13. A pesar de no haber salido en letras de molde, nos es dado conocer el contenido de los seis primeros números previstos, merced a que se conserva el manuscrito de los mismos en AHN, Consejos, 5566-59, s. n. 
Todo ello nos conduce a valorar la idea de que, si bien la Retórica epistolar no iba exclusivamente destinada a las mujeres ${ }^{14}$-puesto que el desconocimiento en la confección de cartas resultaba en España un fenómeno prácticamente universal-, habida cuenta de que su formación escolar solía ser aun menor que la de los hombres, y que por lo tanto habrían de hallarse ellas, en términos generales, más faltas de conocimientos para redactar, sí parece claro que las beneficiaba en una proporción mayor.

Por otro lado, esta de las cartas se nos antoja cuestión recurrente en Marqués, puesto que un año después de la Retórica epistolar incorporó tres misivas en la mencionada "Biblioteca particular del bello sexo Selenítico", del Viaje de un filósofo a Selenópolis: y ya previamente, en el Liceo General del Bello Sexo, había concedido a las cartas una dedicación especial, no solo por plasmar la "Carta de la Pitagórica Melisa a Cleareta" y la "Carta de Téano a Nicóstrata»" ${ }^{15}$, sino por simular la recepción de otras varias, supuestamente remitidas por los lectores (que sabemos inexistentes, al no haberse llevado a cabo la publicación), llegando a transcribir dos de esas falsas epístolas: "Me he resuelto a publicar aquí el billete a una Dama que he recibido con otro (como en contraposición) de un caballero» (Liceo, n. ${ }^{\circ}$ 6, 2. ${ }^{a}$ clase, "Variedades»).

Finalmente, hemos de recordar que no era esta la primera vez que se adentraba Marqués y Espejo por los territorios de la elocuencia, pues diez años antes, en 1793, había dado a la imprenta El perfecto orador; y si con él pretendía fomentar la eficacia en la esfera de la comunicación hablada, ahora con su nuevo libro intentará mejorarla en el ámbito de la escritura. La mecánica expositiva resultó ser en ambos casos muy similar, ya que, a una breve introducción teórica, donde someramente se explicaba el concepto objeto de aprendizaje, le seguía la oportuna ejemplificación, mediante textos traducidos del francés de personajes señaladamente cualificados en la materia ${ }^{16}$.

14. A pesar de lo que acabamos de exponer, tampoco el resto de la producción literaria de Marqués se circunscribía solamente a satisfacer el interés de las féminas, puesto que de ninguna manera se hallaba dispuesto nuestro escritor a renunciar por las buenas a la mitad de su hipotética clientela.

15. Ambas epístolas, junto con una tercera: "Carta de Myia a Filis», conformaron prácticamente el reseñado capítulo "Biblioteca particular del bello sexo Selenítico», y, según creemos, fueron extraídas por Marqués del tomo $\mathrm{V}$ de la Colección de filósofos moralistas antiguos, traducida del francés por ATAIDE y PORTUGAL (1803), en el que aparecían aquellas mismas misivas puestas ya en castellano (Rodríguez Morín, 2018: §19 y 20). A su vez, la fuente de Ataide suponemos que fue el libro de LEVESQUE (1783).

16. Pues, aunque si bien es cierto que la Retórica epistolar se vale en varias ocasiones de cartas en castellano, no lo es menos lo que pone de relieve ARADRA SÁNCHEZ. "La prolongación de la estética neoclásica durante la primera mitad del XIX hará que siga siendo destacable a principios de siglo la abundancia de citas de autores franceses - por encima de italianos e ingleses- en tratados como los de MARQUÉS Y ESPEJO (1803), cuyos modelos están tomados en su práctica totalidad de cartas francesas» (2010: 139). En similares términos se había pronunciado la misma autora unos años antes (2001: 67). 


\section{El TEXTO De Marqués y Su FUENTE FRANCESA}

Al mencionado «Prefacio» le sucedían tres capítulos, siendo el tercero y último el más extenso, y el que recogía una variada tipología de cartas. Por lo que atañe al primero de ellos: "Designio y división de este tratado", hemos de significar que lo iniciaba el autor con una larga cita de su dilecto Feijoo ${ }^{17}$. Y proseguía, luego, manifestando, en una prosa plena de galicismos, que si se había tomado la molestia de traducir "cartas de algunos Literatos de otras naciones» (p. 3), lo había hecho a guisa de cebo, para que la inclusión de figuras ilustres en el arte epistolar, como era el caso Bussy, Sevigné, Maintenon, etc. (p. 4), sirviera no solamente para atraer la curiosidad de las personas más instruidas, sino para que toda clase de gentes procurara la imitación de aquel tipo de literatura, que si bien no trascendía del estilo familiar, había sido objeto de universal admiración. Es decir, Marqués y Espejo con estas palabras nos está proporcionando otra buena muestra de sus inagotables recursos para captar la atención de los lectores.

Aunque, al igual que otros muchos traductores de la época, no acompañaba aquella confesión con otra, si acaso, más relevante, no mencionada por nadie hasta el presente (que sepamos), y que ponemos ahora al descubierto; esto es, que la obra que daba a la luz estaba tomada, en su inmensa mayor parte, de la de Philipon de la Madelaine: Modéles de lettres sur différents sujets ${ }^{18}$, a través de la tercera edición de ese libro, con el título y mucha parte de su interior modificados: Le secrétaire parfait, ou modéles de lettres sur différents sujets, corrigée et augmentée (Venise: Chez Thomas Bettinelli, 1786) ${ }^{19}$.

El segundo capítulo de Marqués: "Nociones preliminares sobre el estilo Epistolar» (p. 5), se corresponde con el del citado libro de Philipon: «Réflexions sur le estyle epistolaire» (p. 1); en ellas manifestaba nuestro presbítero -ciñéndose a la tradicional opinión sobre el tema- que «no es más una Carta que una conversación entre personas ausentes»; de ahí que "el mismo estilo que se usa cuando se habla

17. Recordemos que en 1802 había dado Marqués a la imprenta el Diccionario feijoniano, en el que sintetizaba gran parte de la obra inmensa del monje orensano. Sin embargo, y a pesar del respeto enorme que profesaba Marqués por el benedictino, se permite en esta ocasión contradecirle en cierto modo, ya que dice sentirse firmemente persuadido de "que el conocimiento de las reglas es indefectible en todo arte». Y sostenía ese parecer frente a la opinión de FeIjoo de que, para escribir cartas, se podían suplir los preceptos que las regían, por el tener a la vista buenos modelos de ellas por donde aprender a confeccionarlas (1765: 290; vid. RuEDA, 2001: 143, n. 70). Tal vez ambas teorías pudieran alcanzar un punto de conciliación, en el caso de que Feijoo, a la hora de verter su juicio, tuviera en mente un tipo de destinatario más docto y preparado (pues propone no solo modelos epistolares en castellano, sino también en latín); cuando, en cambio, Marqués, casi 70 años después, pretende llegar, primordialmente, a un género de lector menos cultivado, pero bastante más numeroso. Ponthus.

18. De ese mismo año de 1761, existe también una edición de Lyon: Chez Pierre Bruyset

19. Nos hemos valido en este trabajo de la impresión veneciana de 1786, pero posiblemente haya habido tiradas de esa misma edición llevadas a cabo en otros lugares. 
debe emplearse siempre que se escribe una carta misiva o familiar ${ }^{20}$ (p. 5). Acto seguido, dividía Antonio Marqués este segundo apartado en dos "artículos»; en el primero de ellos: "Motivos para escribir cartas», afloraba una vez más su sempiterna jovialidad y buen humor, ahora por medio de un comentario acerca de la impertinencia de muchos que asedian con cartas innecesarias a sus interlocutores, como pretendiendo ganarse su favor a base de darles la lata (p. 10) ${ }^{21}$.

La otra división o "artículo»: "Tratamiento o Ceremonial de las Cartas», se iniciaba con la alusión a "El pensador matritense», de quien tomaba varios párrafos en los que se criticaba lo huero y vano de las fórmulas de tratamiento, puesto que no pueden ellas menguar ni añadir calidad humana al sujeto a quien van destinadas (pp. 12-18). Y de nuevo asoma la sorna de D. Antonio, cuando, apoyándose en Philipon, señala que un descuido en estos puntos de protocolo para nada afecta si alguien se comunica por carta con un individuo verdaderamente sobresaliente, "pero dirigida casualmente contra un sujeto nuevamente ennoblecido, o que, por el ascenso a su empleo, tiene solamente la posesión del título o tratamiento, no deja de producir un efecto que al que escribe le es perjudicialísimo y de difícil remedio” ${ }^{22}$ (p. 19).

Tal es la razón, asegura Marqués -guiado siempre por el precepto ilustrado de la utilidad-, de haber recogido en este libro suyo «el tratamiento y títulos que deben expresarse ${ }^{23}$ (p. 19). Plasmando, acto seguido, las expresiones de cortesía correspondientes al papa, cardenales, obispos, abades, reyes, príncipes, secretarios

20. Ya PHILIPON se expresaba así sobre este punto: «Une conversation bien réelle entre des personnes absentes» (p. 4), e igualmente: "L'art d'écrire des Lettres, qui devroit être aussi simple que l'art de converser, avec lequel il n'est qu'une même chose, s'est trouvé assujetti à toutes les regles dont il a plu aux Grammairiens de surcharger l'eloquence» (p. 1).

21. Sobre la moda, criticada aquí por Marqués, de escribir cartas superfluas, fruto más de la «necedad" que de la "necesidad» nacida de la lejanía entre los interlocutores, efectúa Mary Trojani la siguiente reflexión: "Pourquoi l'absence doit-elle encourager ou autoriser quelqu'un d'impoli à écrire à une personne à laquelle il n'aurait jamais rendu visite si elle avait résidé près de chez lui? On pèche par l'excès de lettres tout comme par la fréquence des visites. Et nombreux sont ceux qui se livrent à cet abus. La raison essentielle consiste à s'attirer la bienveillance de ceux à qui l'on écrit» (2012, s. n.).

22. Marqués extrae esa reflexión, sin duda, de Philipon: "Manquer à quelques petites formalités, ce n'est pas un crime, dès qu'il n'y a point de mauaise volonté; \& les Grands vraiment dignes de ce nom ne s'en formalisent pas. On a remarqué que ceux qui étoient les plus prompts à s'offender de cette espece de manque d'égards étoient communément ceux que dans le fond en méritoient le moins. Personne n'est plus jaloux du titre de Gentihomme qu'un homme nouvellement ennobli» (pp. 55-56).

23. Y desciende MARQuÉs con tono irónico a otros detalles que, aunque a su juicio innecesarios, parecen ser determinantes en aquellos tiempos que corrían: "No se limita el ceremonial o cortesía de una carta al tratamiento verbal, sino es que se extiende a tanto que la distinción de si debe el papel estar en cuartilla, o medio pliego; el espacio que ha de dejarse para margen; el color de los polvos, de la oblea o lacre, todo esto entra en el enfadoso formulario y decide del despacho favorable o adverso de la respuesta; pero, como la pretendida política del día es interminable, convendrá siempre el no quedarse cortos en semejantes fruslerías» (pp. 31-32). 
de Estado, etc. ${ }^{24}$. Mayor importancia que estos asuntos de protocolo tienen para nosotros sus opiniones sobre el estilo literario de las misivas, "que no deberá ser pesado, ni frívolo, sino seguido y natural ${ }^{25}$; erudito sin pedantería; alegre sin locura; político sin afectación; elegante sin aparato; y chancero sin bajos equívocos [...]. Se habla en ellas de todo; pero no se profundizan las cuestiones para no cansar» (p. 33).

Por tal razón, los retóricos califican ese estilo como ínfimo o simple, en contraposición con el mediano y el sublime. Sin embargo, no debemos caer en la tentación de minusvalorarlo, ya que, según apunta nuestro autor, es menester hallarse bien provisto de destreza e ingenio para materializarlo con esa especie de elegancia "que más bien se deja sentir que notar» (p. 36), conservando sus tres cualidades básicas: "Claridad, Simplicidad y Concisión» ${ }^{26}$ (p. 35). No obstante, y por más bajo que resulte este género de redacción, deben evitarse siempre en él "aquellas palabras groseras que son particulares al vulgo» ${ }^{27}$ (p. 41).

$\mathrm{Y}$ por fin llegamos al punto en el que Marqués y Espejo, dentro de este mismo capítulo III, comienza a exponer los distintos modelos de misivas ${ }^{28}$; un planteamiento este que abarcará hasta el final del libro (pp. 43-274), atendiendo

24. Se trata de una adaptación sumamente libre -y hasta, en algunos casos relativos al tratamiento a emplear, incluso divergente- del epígrafe de PHILIPON: "Ceremonial observé dans les lettres» (pp. 41-52).

25. Dicho requisito de "seguido y natural", preconizado para el estilo de las cartas, pudiera ser considerado, en principio, como una discordancia por parte de MARQUés respecto de su argumentación, expuesta al inicio de libro (pp. 2-4), en cuanto a la necesidad de aprender unas reglas y de guiarse, para su perfeccionamiento, por una serie de muestras de acreditados epistológrafos. Sin embargo, creemos que fue precisamente ese convencimiento de Marqués, de que asimilar y asumir tales requisitos había de resultar un logro sumamente asequible para un lector medio, lo que propició la propia aparición de su tratado; pues suponemos que, de haberla juzgado labor ardua y compleja, su contrastado olfato comercial le hubiera alertado de un probable fracaso en las ventas. Además, contrapone el proceso de la elaboración de las cartas al de otros géneros más exigentes, aconsejando a los respectivos autores que no deben empeñarse en alcanzar meritorios logros literarios, sino que, al revés, «deben escribirse sin trabajo por llenarlas de buenas frases» (p. 33). Sobre estos particulares, RuEDA se pronuncia así acerca del consenso de los retóricos de la época: "Se admite que unas pocas reglas pueden facilitar la internalización de una manera de escribir que, al mismo tiempo, se declara espontánea y natural» (2001: 159).

26. Más de diez años atrás, ya MARQuÉs había ponderado esa modalidad de escritura: «El estilo ínfimo debe ser puro, claro y sin ornamentos aparentes, pero con grandeza y nobleza" (El perfecto orador: 137-138).

27. De nuevo, al fondo de todas estas disquisiciones, encontramos a PHiLipon, el cual, en sus "Reflexions sur le estyle epistolaire» (pp. 5-31), atribuye al estilo epistolar tres características fundamentales: «Simplicité, aisance et ornaments», y alaba en él su sencillez (pp. 5-14), la naturalidad (pp. 14-21), así como el uso muy moderado de los recursos retóricos (pp. 22-31); del mismo modo, proclamaba la exclusión de las rimbombancias y complejidades del pensamiento (pp. 16-19), a la par que tiraba tanto contra el estilo elevado y pedante (pp. 12-14) como contra el demasiado bajo, portador de ordinarieces y trivialidades, por completo ajeno a cualquier regla gramatical (pp. 11 y 14-16).

28. Marqués omite el capítulo de Philipon: "Caracteres des Auteurs les plus connus dans le genre epistolarie» (pp. 32-42), en el que el compilador francés consignaba las fuentes de las que extraía 
en total doce tipos distintos, y 106 misivas. El esquema, dentro de cada uno de dichos epígrafes, será siempre el mismo. Pues cada clase de carta a tratar se inicia con unas "Reglas generales», que suelen ocupar dos o tres páginas, a las que sigue un elenco de textos, generalmente (aunque hay alguna excepción) entre cuatro y siete, pertenecientes a personas -en su gran mayoría francesas- que destacaron con talento y disposición en ese oficio, para luego finalizar, en algunas ocasiones, pero no en todas, con una "Respuesta" ${ }^{29}$ a esa suerte de misivas, aportando tres o cuatro ejemplos por cada caso ${ }^{30}$.

Hemos de señalar ahora una cuestión atinente al manual de Marqués que nos parece llamativa, pues incide en un ingrediente sustancial de las cartas, tal cual es el de su fecha y la localidad desde la que se escribe la misma, ya que nos parece harto significativo el hecho de que omita esos pormenores en la inmensa mayor parte de los textos tomados de Philipon ${ }^{31}$. Sin embargo, en las misivas que recoge de comunicantes españoles aparece la data prácticamente en todas ellas.

Ignoramos si ese proceder obedecía a una razón en particular, aunque podríamos conjeturar que podría deberse a un intento de Marqués por que su obra no pareciera alejada de la realidad concreta en la que surgió y, por consiguiente, de los lectores que habrían de manejarla; procurando, al menos, la cercanía geográfica en los escritos hispanos y evitando la lejanía temporal en los foráneos. En provecho de este argumento, se ha de precisar que en las tres únicas oportunidades en que se estampó la fecha en los ejemplos provenientes del país vecino, solamente en uno se facilitaba completa: "Carta del conde de Bussy Rabutin al P. Rapin, Bussy: 22 de Diciembre de 1677» (p. 73); pues las otras dos misivas: «Carta del Padre Bouhours al Conde de Bussy: París 6 de Febrero de 75» (p. 67) y «Carta de Madama de Maintenon a Madama de Chantelou: París 28 de Abril de 66» (p. 70), como no reproducían el siglo en su transcripción, podían pasar por casi coetáneas del libro de D. Antonio. Esta hipótesis cobra más valor si comparamos esta

sus cartas, junto con algún breve comentario sobre los respectivos autores, y donde aportaba incluso algún dato sobre la edición manejada.

29. Es el mismo esqueleto que compone Philipon, que denominaba "instruction" al primero de esos elementos. Si bien, Marqués no se valió nunca del epígrafe «fragments", presente en aquel al final de cada tipo de carta, donde se plasmaban únicamente partes de distintas epístolas.

30. El desglose es el siguiente: "Cartas de consejos, serias y morales»: 7; "Cartas de pésame»: 7 más 3 respuestas; "Cartas a las Personas de cuya compañía nos separamos»: 3; "Cartas de negocios y encargos particulares»: 4; "Cartas de recomendación»: 7 más 2 respuestas; "Cartas de pretensión, representaciones y memoriales»: 5; "Cartas de gracias»: 5 más 5 respuestas; "Cartas de enhorabuena»: 8 más 3 respuestas; "Cartas de pascuas, días y año nuevo»: 12 más 4 respuestas; "Cartas de noticias»: 10: "Cartas de quejas o resentimientos»: 6 más 6 respuestas; "Cartas del amor honesto»: 4 más 4 respuestas (o 5 si se atiende al caso de que una de ellas contiene doble contestación y dos remitentes).

31. En cambio, el autor francés no obvia nunca esta circunstancia, puesto que, tal y como había anunciado en "Cérémonial observé dans les lettres", uno de los apartados iniciales de su libro: "La Date se place indifféremment au haut ou au bas d'une Lettre. On dit que la seconde manière est plus polie; je trouve la premiére plus commode» (p. 43). 
edición con la de 1819, en la que son mucho más abundantes los ejemplos de cartas salidas directamente de su pluma, quedando impregnado, así, el conjunto de la obra de una mayor confinidad con su concreta circunstancia y, en definitiva, con los adquirentes del libro.

Al contrario de lo que sucede con el caso de la datación ocurre con el de las fórmulas de inicio y final de las cartas: escasísimas en Philipon (casi únicamente en las concernientes a personajes de gran relevancia, como reyes o prelados eminentes) y bien abundantes, por contra, en Marqués. Es decir, que este añadió, sponte sua, las formas de salutación y despedida como mejor entendió.

De ahí que, en cuanto a las de comienzo, sea frecuente encontrar expresiones del tipo: "Amado hermano» (p. 63), "querida hija mía» (p. 75), «Mi estimado conde» (p. 116), «mi verdadero y constante amigo» (p. 127), «mi compañero y amigo» (p. 202), etc. En otras ocasiones, la actitud se torna bastante más formal, aun sin existir mucha razón para ello por tratarse de correspondencia entre iguales: «Señora Marquesa: Muy Señora mía» (p. 95), «Exmo. Señor» (p. 118), «Muy Señor mío» (p. 155), «Señora» (p. 206), etc.

Por lo que atañe a los enunciados de despedida, Marqués recurre de nuevo a su imaginación, pues van desde un simple: «quedando su \&c.» (p. 249), hasta manifestaciones decididamente complejas: «Me contento con ser amigo de Vm. por cuya vida y tranquilidad ruego a Dios nuestro Señor \&c.» (p. 69), o «una mano que estimo tanto y la que B[eso]. con un afecto muy respetuoso \&c.» (p. 156), pasando por otras terminaciones más habituales: «tu hermana que más te estima» (p. 65), «mientras viva será tuya, tu Mamá \&c.» (p. 76) o «Dios nuestro Señor guarde a Vm. muchos años \&c.» (p. 207) $)^{32}$.

Como era de suponer, estas fórmulas añadidas por Marqués en las cartas que traslada del francés no difieren en mucho de las que figuran en las misivas redactadas enteramente por él, y que colocó al final de su libro; si acaso se nota aquí,

32. Respecto de este particular asunto, EARLE (2005), tras examinar 361 cartas escritas por hombres, la mayor parte de ellas pertenecientes a los siglos XVII y XVIII, afirma que: "these reveal that the most common salutation use by husbands in the sisteenth century was "mi señora" ("my lady"), which was railed in popularity by "hermana mía" ("my sister")». En cambio, en el siglo 18 "the most common salutation was "mi esposa querida" ("my dear wife"), followed by "mi hija querida" ("my dear daughter")». Por lo que acontece a las fórmulas de cierre, Earle apunta lo siguiente: "In the sixteenth century the most common closing was "vuestro marido" ("your husband"), or "el que más que así os ama/quiere" ("he who loves you more than he loves himself"), while in the eighteenth century the most common closing was "tu esposo" ("your spouse"), followed by "quien de corazón te quiere y estima y desea ver" ("he who from his heart loves and esteems and wishes to see you") ("or some subset of this phrase")" (p. 31). Un poco antes, la misma autora se había hecho eco de la percepción, existente en la época, de que las cartas españolas solían diferenciarse de las demás precisamente en esas cláusulas de inicio y fin: "In Spain, as elsewhere in Europe, letter-writing manuals detailing correct forms of address were published from the sixteenth century on. Many of these works emphasized the distinctive nature of Spanish salutations and closings, which one eighteenth-century manual characterized as "so different from that of the other nations"» (pp. 29-30). 
en esta aportación más personal, una mayor libertad en los textos remitidos por los caballeros a las damas, especialmente en el acto de la despedida, puesto que si la salutación quedaba encorsetada por los signos típicos del respeto, en donde imperan frases como: «Mi Señora Doña» (pp. 256 y 259), «Mi estimada Señorita» (p. 260) o "Muy Señora mía» (p. 263), es en la conclusión del mensaje cuando nuestro autor se toma la licencia de desenfrenar la péndola muy a su sabor: «ruego a Dios nuestro Señor la guarde muchos años» (p. 258), "Mande con franqueza a este su seguro y apasionado servidor, que se ofrece a S. P. \&c.» (p. 260), "su tierno amante y apasionado servidor que nunca dejará de ser de Vm. \&c." (p. 262), "su afectísimo servidor y futuro esposo" (p. 265).

Las señoritas, por su parte, tanto en el principio como en el fin de sus respectivas contestaciones, mantienen una posición bastante más formal, y fuera de un "Mi buen Teniente Coronel» (p. 270) -que en nada rebasa la tibia confianza-, relativo a la respuesta de la carta tercera, las otras tres no pasan de un frío y distante "Muy Señor mío» (pp. 266, 269 y 271), resultando el remate más frecuente el de «su reconocida servidora» O "Su segura servidora» (pp. 267, 270 y 271).

Marqués, en las otras doce ocasiones en las que se aparta de Philipon, con el fin de insertar cartas españolas, recurrió a dos compilaciones de Mayans y Siscar, la primera, de 1733: Cartas de D. Nicolás Antonio y de D. Antonio de Solís. Añádese una de D. Cristóbal Crespi de Valdaura, y la segunda, de 1734: Cartas morales, militares, civiles y literarias de varios autores españoles; de entre ambas dos colecciones, traslada siete cartas de Antonio Solís, dos de Quevedo, una del patriarca de Antioquía, una de la duquesa de Villahermosa y otra más de Paulo Albiniano de Rajas.

\section{LA CLASIFICACIÓN DE LAS CARTAS EN LA RETÓRICA EPISTOLAR}

Dejando de lado, por el momento, el último epígrafe de Marqués, concerniente al "amor honesto "33, en el que todo parece ser original suyo y nada hay de Philipon, hemos de poner de manifiesto que el libro dio cabida a 97 cartas, 85 de las cuales fueron traducciones de dicho autor francés. Merece la pena señalar que, del conjunto de todas ellas, 26 pertenecían a mujeres, resultando la marquesa de Sévigné con 9 y madame de Maintenon con 6 las que más misivas aportaban a la nómina femenina. A estas 26 misivas se han de añadir las cuatro finales que aportó Marqués de su coleto, lo que supone un total, entre reales y fingidas, de 30 textos firmados por damas ${ }^{34}$.

33. En él, como ya dijimos, dejó plasmadas Marqués nueve epístolas, que más adelante examinaremos en detalle.

34. Un dato este que SÁNCHEZ EsPINOSA conecta con una mayor preponderancia social de la mujer: «En el manual epistolar de Marqués y Espejo, el mayor número de modelos escritos por autoras reconocidas y personajes femeninos -treinta de un total de ciento tres cartas- con respecto al Nuevo 
Había iniciado Philipon el desarrollo de sus cartas con las "Lettres d'Affaires» (pp. 57-66), puesto que sigue el orden alfabético en todas ellas, pero, sin embargo, Marqués lo hizo con las "Cartas de consejos, serias y formales", que se corresponderían con las «Lettres serieuses et morales» (pp. 373-417) -curiosamente las últimas en su fuente gala- ${ }^{35}$ y las "Lettres de conseils» (pp. 119-138). En cuanto a sus "Reglas generales» (pp. 43-46), nuevamente vuelve el español a adaptar libremente las reflexiones de Philipon, con el que coincide de lleno en que este tipo de comunicaciones deben escribirse en un estilo simple y sin retóricas.

En ese breve pasaje introductorio, Marqués nos da ya algunas pistas valiosas sobre lo que será una constante a lo largo de todo su tratado; es decir, un modelo de prudencia, sabiduría y profundo conocimiento del ser humano, guiado por la perpetua batuta de la utilidad: "Debemos aconsejar a otro siempre que nos pida el Consejo, cuando conozcamos que le desea, o creamos que ha de ser bien recibido. La carta que no esté formada sobre este principio será siempre intempestiva" (p. 43). Como ejemplo de esta suerte de escritos, escogió Marqués seis cartas, de entre otras muchas de Philipon, y estampó una, española, con la que abrió la serie, y que contaba con 16 páginas, en extremo extensa para lo acostumbrado luego en la obra ${ }^{36}$. Se trataba de una carta enviada por Cristóbal Crespi de Valdaura a su hermano Juan Crespi, fechada en Valencia el 12 de mayo de 1627, trasladada prácticamente de forma literal de la citada recopilación de Mayans (pp. 115-128). Por otra parte, y como patrón constante en Marqués de acercar lo mejor posible su obra a los lectores, hemos de reseñar el hecho de que, dentro de este primer grupo de misivas, concretamente en la "Carta de Madama Maintenon a su hermano", convirtió Marqués las 3.000 libras del original (Philipon, p. 124) en 12.000 reales (p. 63).

Sucedían a las anteriores las "Cartas de pésame» (Lettres de condoléance» en Philipon, pp. 93-118). Proponía en ellas el sacerdote hispano, al igual que su modelo francés, el remedio de la religión como terapia por parte del remitente para consolar a un afligido destinatario. Pero la experiencia le lleva a reiterar el laconismo en este método: "porque las reflexiones morales y de religión suelen fatigar muy prontamente a las gentes del siglo» ${ }^{37}$ (p. 78). Además, otra particularidad de la personalidad de Antonio Marqués se nos muestra ahora: la de su portentosa capacidad de empatía ${ }^{38}$, pues sugiere «manifestar al principio [de la misiva] que se

\footnotetext{
formulario, manifiesta la ampliación o incluso la ruptura del espacio epistolar tradicional, en correspondencia con un mayor protagonismo social de la mujer» (2001: 122-123).

35. Tal parece que Marqués organizó sus apartados con la idea de evitar cualquier coincidencia con el orden establecido por Philipon.

36. No sabemos si fue un gesto deliberado este de inaugurar la larga nómina de misivas con una escrita originalmente en castellano.

37. En términos muy parejos se expresaba PHILIPON: «Je ne crois pas qu'il soit besoin d'avertir que ces réflexiones doivent être courtes. Les moralités fatiguent, \& l'on s'endort aisémente au sermon» (p. 94).

38. A este respecto, puede consultarse RODRÍGuEZ MORÍN (2017: 321-332).
} 
toma parte en su justo sentimiento. Así se lee con más gusto lo que uno escribe» (p. 78). Siete cartas de este género y otras tres en "Respuestas a las cartas de pésame» ilustraban el capítulo. Entre las primeras figuraba de nuevo alguna española, como la del arzobispo de Antioquía al condestable de Castilla (Valencia, 1 de abril de 1607), obrante en la referida recopilación de Mayans de 1734. De otra parte, en la "Carta del Conde de Bussy a Madama de D... Sobre la pérdida de un Pleito", volvía a transformar Marqués una expresión típica francesa: "contre fortune bon coeur» (Philipon, p. 100), en otra bien castellana: "a lo hecho, pecho» (p. 89).

Las "Cartas a las Personas de cuya compañía nos separamos» eran las dedicadas a agradecer al anfitrión su hospitalidad, una vez alcanzado el destino final. A propósito de ellas, «las más capaces de toda la gracia y adornos del estilo Epistolar» (p. 94), apuntaba Marqués, por su cuenta, alguna que otra consideración ausente en Philipon ("Lettres de séparation, ou a une personne qu'ont vient de quitter», p. 363), como es el caso de que pueden pintarse "ciertas particularidades ocurridas en las Posadas y caminos; los Lugares que se ven al paso; y sobre todo algunas expresiones lisonjeras sobre el sentimiento ocasionado por la separación» (pp. 93-94). Sin embargo, tampoco en eso es nuestro autor original, pues creemos que esas observaciones vienen producidas por las cartas que el propio Philipon ponía como ejemplo, especialmente la "Carta del caballero de Sant Verán a la marquesa de...» (pp. 95-96).

En cuanto a las "Cartas de negocios y encargos particulares", anota D. Antonio que "la concisión y claridad deben ser su divisa y distintivo" (p. 101). Al igual que Philipon, refiere que ha de entrarse en materia sin preámbulo alguno, y a semejanza de él efectúa la advertencia de que los asuntos demasiado importantes no deben confiarse a este método, puesto que «es muy corta seguridad la que ofrece una oblea" (p. 101). Además, nuestro avisado capellán, en un pensamiento de su propia minerva, pondera la cautela, ya que «el amigo, a quien se le dirige, podrá dejar de serlo con el tiempo, y siempre por el papel se está diciendo lo mismo» (p. 101). Para ilustración de esta especie de epístolas, introduce, junto a un par de ellas plasmadas por Philipon, otras dos españolas, pertenecientes ambas a D. Antonio de Solís, dirigidas a D. Alonso Carnero (pp. 102-104 y 105-108), una vez más copiadas de la citada obra de Mayans (1733: 84-86 y 80-83). Y de nuevo, en una de las de Philipon, concretamente la de Racine a Boileau, Marqués transforma las «cuatre lignes» (p. 269), en «dos letras» (p. 111), en ese sempiterno afán de aproximar los textos a sus destinatarios.

Las observaciones de Marqués y Espejo sobre las «Cartas de recomendación» (pp. 114-116) suponen, en cambio, una significativa separación del sendero marcado por Philipon en sus "Lettres de recommandation" (pp. 298-299), pues aquel las consagra en mucha parte a lanzar una contundente crítica social, censurando el hecho de que una gran parte de personas importantes otorguen recomendaciones sin conocer siquiera los méritos del futuro beneficiario, en perjuicio de quienes verdaderamente poseen un talento que podía emplearse en provecho de la nación, un apaño aquel del que tanto se abusaba y que "acarrea infinitos daños» (pp. 114-115). 
La intención constante de nuestro autor de acercar las letras extranjeras a la realidad hispana, así como su gusto y afición por los proverbios, los refranes o los dichos populares, se echa de ver otra vez en la traslación de la "Carta de Mr. Boursaut a Mr. de Quanteal; Médico», al escribir lo siguiente: «Su fisonomía basta para hacerle pasar por un buen Juan» (pp. 122-123), cuando, en el pasaje reproducido por Philipon, leemos: «Sa physionomie suffit pour justifier qu'il n'a point de méchans desseins» (p. 303). Por otra parte, dejó sin traducir uno de los ejemplos puestos por Philipon, pero a cambio inserta dos cartas de Antonio Solís a Alonso Carnero (pp. 119-122), valiéndose, seguramente, de la ya mentada compilación de Mayans, de 1733 (pp. 60-61 y pp. 62-63).

En lo relativo a las «Cartas de pretensión, representación y memoriales», continúa Marqués interpretando a Philipon en sus "Lettres de demande et placets» (pp. 139-142), y aconsejaba «emplear un estilo que se deje leer con gusto; ser en la carta o memorial conciso, sencillo y modesto" (p. 129). Además de las misivas vertidas de su modelo francés, Marqués introdujo una que Francisco de Quevedo había escrito, desde su prisión, al conde-duque de Olivares, y que, aunque no va fechada, sabemos que es de 7 de octubre de 1641.

En las "Cartas de gracias», nacidas de haber recibido un favor, Marqués coincide con Philipon en que "el estilo debe ser el del corazón»; por otro lado, este tipo de escritos son "muy susceptibles de expresiones vivas y brillantes» (p. 148). En lo concerniente a los ejemplos de esta especie de textos, o más precisamente dentro de las "Respuestas a las cartas de gracias", se da el caso curioso de que Marqués mantuvo una de Voltaire (al que Philipon nombra más de 20 veces a lo largo de su libro), aunque naturalmente camuflando su identidad: "Respuesta de Mr. V. al Cardenal Alberoni» (pp. 157-158). De semejante tenor ocurre con Rousseau, puesto que aun cuando se trata de Jean Baptista, y no de Jean Jacques, Marqués no deja de tomar diversas medidas precautorias, como la de especificar, cuando está seguro de ello, que no se trata de este último, pues claramente se mencionaba así en el encabezamiento de Philipon: "De J. B. Rousseau à M. $\mathrm{D}^{* * * *}$, sur la mort de son Fils ainé» (p. 106); de ahí que nuestro escritor estampe por nota al pie de página: "Se advierte que este Rousseau es diferente de J. J. Rousseau» (p. 82). Otras veces, en caso de duda, Marqués esquiva el dichoso apellido, anotando solo la inicial, cosa que hace, por ejemplo, con la "Carta de R. a Mr. Boutet» (p. 153), o "De Rousseau au comédien Baron» (Philipon, p. 341), que nuestro autor recoge como «Respuesta de R. al Cómico Varón» (pp. 160-161).

Se muestra también conforme Marqués y Espejo con el parecer de Philipon cuando en las "Cartas de enhorabuena" (pp. 162-163), o "Lettres de félicitacion" (Philipon, pp. 233-234), señala que «debemos tomar parte en los motivos de alegría que ocurren a nuestros amigos, parientes o protectores» (p. 162), matizando el hecho de que «son fáciles de escribir estas cartas cuando las dicta verdaderamente la amistad o la gratitud; pero exigen más arte y precaución cuando la política y urbanidad únicamente las forman» (p. 163). Entre las misivas con las que se ejemplifica esta especie, introduce Marqués una de Quevedo al duque del Infantado, 
casa nobiliaria a la que tantos favores debía nuestro ilustrado, y otra más de Antonio Solís a Crispín González. Además, la "Carta de la Duquesa Du Maine al Duque de Bandoma» constituye una ocasión más de esa constante inquietud del español por acercar a sus compatriotas las expresiones francesas, recurriendo a su inagotable trastienda de refranes, pues donde el original decía: «Á propos du proverbe: A grands Seigneurs peu de paroles» (241), Marqués recogía lo siguiente: "En burlas [sic] ni en veras con tus mayores no partas peras " 39 .

Las doce "Cartas de pascuas, días y año nuevo", junto con las cuatro respuestas, conforman el conjunto más numeroso de la obra. En este caso D. Antonio, que se sale bastante del guion de su fuente gala: «Lettres de bonne année» (pp. 67-69), se aplica, perspicaz, en resaltar la hipocresía barata que las alumbra: «El uso de los cumplimientos es una especie de comercio de mentiras de oficio, que por lo regular a nadie engañan, pues hay poquísimas personas que no las tomen por lo que valen» (179-181). Y haciendo uso de su buen humor, inserta unos versos divertidos con los que un poeta anunciaba el año nuevo a un amigo calvo: "Reduzco todo mi anhelo / A que al fin veas sin daño, / Mejores entradas de año, / Que las que tienes de pelo» (pp. 180-181) ${ }^{40}$.

Tampoco en la introducción teórica de las "Cartas de noticias» siguió Marqués de cerca a Philipon en sus "Lettres de nouvelles» (pp. 281-284). Clasificaba nuestro escritor las noticias en tres tipos: "tristes, indiferentes, o alegres", y proponía el adoptar ciertas precauciones en cuanto a la comunicación de la primera de ellas, especialmente si se trataba del fallecimiento de algún ser querido del receptor de la misiva: "Lo mejor es prepararles con una carta que les quite la esperanza, y en el inmediato correo dirigirles otra que con claridad les participe el triste suceso" (pp. 199-200). Tal vez cuando esto escribía, estuviera pensando nuestro antiguo capellán castrense en las ocasiones en que hubo de vivir personalmente ese doloroso trance de participar, por carta, a los familiares la muerte de algún soldado caído en la guerra de la Convención.

Por lo que atañe a las noticias indiferentes, que generalmente se corresponden con novedades políticas, Marqués observa que «no piden el orden seguido ni el estilo relevante de los papeles periódicos, por lo que, sin más que haciendo separación de párrafos, se tratan en ellas diferentes asuntos sencillamente, sin transiciones» (p. 200). En cuanto a las alegres, «es superflua cualquiera prevención, porque de todos modos son siempre bien recibidas» (p. 200).

39. El refrán en su versión original era políticamente menos correcto: «Ni en burlas ni en veras con tu amo [o señor] partas peras".

40. Como cuestión curiosa, hemos de traer aquí a colación la felicitación contenida en cierta carta de Fléchier a Madame de C, por el nuevo año que comenzaba, puesto que, fechada en el texto de Philipon el 26 de diciembre de 1708, se iniciaba así: "Quand je vous souhaite, Madame, au commenement de cette année une longue suite de jours heureux" (p. 74); en cambio, Marqués la convirtió en una congratulación por la onomástica de su destinataria: "Cuanto deseo a Vm. en este día de su Santo una larga serie de semejantes días» (p. 191). 
Pero no concluía con tales precisiones dicho epígrafe, sino que, al hilo de lo dicho, parece como si Marqués se sintiera en la necesidad de exponer algunos mecanismos propios de su menester de escritor:

Porque en esta especie de cartas es donde más se emplea la Narración; debo advertir que esta es la exposición de un hecho; que aunque consta de las infinitas cualidades con que los Retóricos han querido recargarla a proporción del estilo en que se emplea, en el ínfimo, de que se habla ahora, como el único conveniente al epistolar, la narración debe (como él mismo) ser simple y breve; quiero decir: que si hacemos en una carta la relación de un hecho, debemos contarle simple y brevemente ${ }^{41}$ (p. 201).

En gráfica constatación de lo expuesto, aprovecha D. Antonio una carta de Racine a Boileau, previamente plasmada por Philipon, para, a la mitad de la misma, estampar en letra mayúscula entre paréntesis el rótulo: "Ejemplo de narración", inexistente en la versión original (pp. 291-293), con el fin de contar, a partir de ese momento, las vicisitudes de un fusilero al que las balas enemigas le privaban de los sucesivos salchichones que iba cogiendo. Esta particularidad se halla también presente en otras varias cartas suyas, en las que emplea o bien la misma etiqueta de antes, o bien la de "Narración de la misma", o ya simplemente "Narración»"

En las "Cartas de quejas o resentimientos" recogía Marqués las "Lettres de reproches» (pp. 195-197). Sin embargo, únicamente coincidía con Philipon en la prudencia al empuñar la pluma. Ponía el autor hispano el acento de estas cartas en la dignidad del individuo, quien al sentirse defraudado ya por un amigo, ya por una persona principal, no ha de sufrir en silencio el desaire y la desazón, que a la postre podía llevar a los causantes a despreciar, por insensible, al agraviado; sino que ha de hacerles a estos partícipes de su disgusto bien claramente. Pero, eso sí, valiéndose de la precaución y de la prudencia. De ahí que recomiende esperar unos días para no afrontar en caliente el problema, "y sin ninguna furia, hacer verles la cuestión desde una perspectiva indulgente, pues no conviene romper lazos con quien el día de mañana nos puede echar una mano» (p. 227). Como se ve, Antonio Marqués y Espejo nos vuelve a demostrar así su mundología y conocimiento profundo del alma humana.

41. En el reseñado El perfecto orador (1993), ya refería MARQUÉs las siguientes consideraciones: "La narración es la exposición de un hecho. Exige tres condiciones: Simplicidad, brevedad y probabilidad. Simplicidad, esto es, que no tenga reflexiones difusas, ornamentos sobresalientes, figuras brillantes, ni raciocinios extendidos [...]. La brevedad, que debe medirse, no por el número de las palabras, sino por la exactitud a decir solamente lo necesario [...]. La probabilidad, que consiste no solamente en no decir cosa increíble, sino es en atribuir a las personas su carácter propio, y a las acciones, el grado de verisimilitud suficiente a no dejar lugar a exageraciones» (p. 54).

42. Por otra parte, fuera ya de la jurisdicción de Philipon, MARQués torna a reproducir otra epístola de Antonio Solís a Alonso Carnero (pp. 207-211), en la cual eliminaba unas cuantas líneas respecto de la estampada en la citada colección de MAYANS (1733: 98-101), seguramente por no resultarle de interés. 
Entre el muestrario de cartas, y junto a la consabida serie aportada por Philipon -de la que Marqués soslaya una de Voltaire-, facilita nuestro autor dos de remitentes españoles: una, de Antonio Solís a Alonso Carnero, y otra, de Paulo Albiniano de Rajas al marqués de Aitona ${ }^{43}$.

Tras estas de "quejas o resentimientos», colocaba Antonio Marqués las «Respuestas a las cartas de quejas", cuyos textos ilustrativos se correspondían con los que Philipon insertaba para ejemplificar sus «Lettres de excuses» (pp. 195-197), ya que el tratadista francés examinaba estas cartas dentro de un tipo distinto, con sus propios patrones y modelos.

Y llegamos, así, a la última de las categorías analizadas por el presbítero alcarreño: la de las "Cartas del amor honesto", en las que por entero se desliga de Philipon, quien no incluye este género de escritura en ningún momento. De ahí que los textos que conforman esa lista sean muy probablemente composiciones originales de Marqués ${ }^{44}$; por tal motivo, y por otras razones que también veremos, creemos que merecen un apartado propio.

\section{El CAPÍtUlo final Del libro: Un TOQUe PERSONAL De MARQuÉS}

Con el compendio ya prácticamente concluido, parece que quiso nuestro autor engalanarlo con un broche de oro que lo dotara de un aire de frescura y de una amenidad que el resto del libro no poseía sino a cuentagotas. Resulta también el epígrafe más extenso, y en el que Marqués vuelca su imaginación de escritor con el presumible fin de darle un aspecto más costumbrista y moderno a lo escrito, y dejar más gustoso con su lectura al común del público, quizá un poco saturado de fragmentos poco atentos a sus particulares circunstancias. Por otro lado, en esta fase final de su empresa puede detectarse el embrión de las profundas novedades que introdujo en la segunda edición de su Retórica epistolar. Por todo ello, se podría calificar este apartado como una especie de microobra dentro del mismo libro.

Y lo comenzaba Marqués, curiosamente -tal vez por no hallarse presente este en su fuente gala-, como si estuviera obligado a dar explicaciones sobre esa inclusión en su manual: «Tal vez es este [del amor] el motivo por que más se ha ejercitado la pluma en el mundo; y el deseo de la exactitud en este tratado nos obliga a tocar semejante materia» (p. 250). A pesar de dicho argumento, nos maliciamos

43. Obrante en la citada colección de MaYAns (1734: 120-124). De ahí tomamos el nombre de Aitona para el marqués, puesto que Marqués había omitido su identidad, sustituyéndola por unos puntos suspensivos.

44. Y es que, tratándose de Marqués y Espejo, nunca podemos ser rotundos en afirmar que una determinada composición sea genuinamente suya, puesto que, como señala ÁLVAREZ DE MIRANDA (1995: 200), nuestro autor era «un experto en piratear libros»; cuestión esta que, sin ir más lejos, queda sobradamente de manifiesto en el caso de la propia Retórica epistolar. 
que una de las causas de tal incorporación concernía más bien al capítulo crematístico, al que nunca nuestro escritor mostró empacho ${ }^{45}$; así también se infiere, en el fondo, de sus propias palabras: "Faltaría el capítulo que con más ansia buscarán varios curiosos en nuestra obra sino hablásemos en ella de la pasión» (p. 250). Aunque, como pronto veremos, no será esa la única razón que, a nuestro juicio, empujó a Marqués a insertar dichas páginas.

Eligió D. Antonio para adentrarse en ellas un asunto que, según más atrás anotamos, le preocupaba muy seriamente: el de las funestas consecuencias que podría acarrear a la mujer una decisión imprudente. Pues, si bien admite que en muchas ocasiones las cartas desempeñan un papel fundamental para forjar un matrimonio, «debe ser tanta la escrupulosa precaución con que el bello sexo tome la pluma para este asunto que le exhortamos a que jamás llegue a hacerlo sin la consulta y aprobación de las personas a quienes por obligación deben las señoras estar sometidas» (p. 251). Y tal vez influido por las dolorosas situaciones conocidas en función de su empleo como capellán en la Real Casa de Recogidas, fueran fruto las siguientes palabras: "La soltera desgraciada, que, con temeraria imprudencia, se separó de sus luces y experiencia en este importante particular, ha pagado siempre a un precio muy caro la ligereza de su proceder» (p. 252).

Además, en abundancia de esa argumentación, recurre también a la literatura: "Nos presentan las Historias innumerables ejemplos del terrible castigo experimentado por algunas mujeres fáciles en entregarse a un comercio Epistolar» (p. 252); lo cual le acaba llevando de nuevo, tras algún circunloquio, a su experiencia personal: "El inmortal Richardson destinó varios tomos para imprimir en el corazón de las Damas la importancia de esta máxima a que las persuadimos, remitiéndolas a la lectura de: Miss Clara Harlowe, cuya preciosa Historia poseemos ya traducida" (pp. 252-253); e inserta Marqués acto seguido una nota al pie de página: "Y yo tengo concluido el Drama en verso de esta misma Historia, que daré a luz prontamente» ${ }^{46}$.

Se entretiene después en considerar que para comunicar sentimientos en este género de escritos es, con mucho, preferible hallarse preso del amor, aun siendo iletrado, que resultar muy culto y no albergar pasión alguna. Por eso aboga por la naturalidad: "Cuando la verdad, el interés propio y, sobre todo, la inclinación amorosa rigen la pluma, no hay más que dejarla con la seguridad de que irá bien» (p. 255). Esto es, cuando al amador le toca reflejar por escrito sus emociones no le hará ninguna falta saber de retóricas, puesto que «ni el más rudo necesita de reglas para escribir bien este género de cartas; pues cuando habla la pasión, se exprimen sus sentimientos con un estilo que el más instruido no podrá igualar»

45. Recordemos las palabras de MARQués en su desenfadado «Prólogo un poco a la violeta [...]»: «Dichoso yo, si con esta obra, me procuro algunos reales!", en Desahogos líricos de Celio, dedicados al dios Apolo (1802: VII).

46. En efecto, al año siguiente, 1804, salió de la estampa Miss Clara Harlowe [...] 
(p. 253). Ahora bien, a la vista de estos ejemplos, podemos preguntarnos por qué, si en tales supuestos no resulta necesario el conocimiento de este tipo de artes, inserta nuestro clérigo este capítulo en un libro en el que justamente se tratan las técnicas para ejecutar con mayor efectividad las cartas.

La respuesta a esta contradicción viene dada, posiblemente, por las razones que antes adujimos, relativas a ese afán por modernizar de alguna manera la obra y de pretender captar la atención de un número mayor de lectores, adentrándose de lleno en el tema sentimental, de tanto atractivo y ponderación en la época. Y así es que, tras la reseñada introducción teórica, nos presenta Marqués cuatro misivas, en las que, buscando la diversidad en el remitente, intenta atrapar nuestra atención y mantener la intriga hasta el final del volumen, pues no es sino hasta allí donde hallan respuesta todas esas cartas.

En la primera de ellas, "De un Filósofo a una Señora", valiéndose de la condición de pensador del pretendiente, planteaba Marqués una circunstancia social que podía suscitar polémica, y de un modo especial precisamente en personas acostumbradas a discurrir de manera independiente: «No comprehendo el por qué ha de exigirse de nosotros que al intento de tomar estado nos hayamos de ver reducidos a tratarlo primero con los padres de la dama, sin que sepamos antes de ella su intención verdadera» (pp. 256-257). Aunque, ha de matizarse que la libertad que se procuraba alcanzar llegaba, en la perspectiva de Marqués, únicamente hasta ese punto, para acatar luego la posterior voluntad de los progenitores: «Negarme a la obediencia que por todo derecho se les debe sería un atentado indigno de mi honor, y también poco honroso a la prudente delicadeza que quiero en la persona a quien más amo y estimo" ${ }^{47}$ (p. 258).

La segunda epístola corresponde a un caballero que se dirige también directamente a la dama, pero haciendo la manifestación de que, con anterioridad, había frecuentado a sus padres con el fin de, algún día, pedirla a ella en matrimonio (pp. 259-260). En la siguiente, tercera de la serie, su autor reconoce que ha carecido de la entereza suficiente para declararle su amor en persona, y que solamente por medio de aquella carta podía abrirle su corazón. Curiosamente, quiso Marqués adjudicar dicha falta de valor a un militar, así como la condición de huérfana a su pretendida, por lo que ni siquiera tendría que haber pedido él licencia a sus padres (pp. 260-261) ${ }^{48}$.

Por lo que hace a la última de las misivas: "Cuarta carta. De un Mayorazgo al mismo intento, en la que se incluyen varios defectos que deben evitarse, y se notarán en su respuesta», conforme el propio título avanza, aglutina una serie de

47. Esta carta figura fechada en "Jérica y Junio \&», sin expresión del año, y es la única de las cuatro que menciona la data.

48. Ignoramos si esta inofensiva mengua de osadía por parte de un oficial del ejército pudo resultar una especie de broma o chanza hacia su hermano Fernando, quien a la sazón había sido teniente en el Regimiento de Toro. 
elementos que buscan la repulsa del lector hacia el redactor del texto, para, de ese modo, dejar más en suspenso a aquel, y mantenerlo intrigado hasta el final, donde tiene lugar el desenlace de la historia. El asunto, en sí, trata de un sujeto de muchos posibles que, preterido por cierta dama, buscaba su revancha dándole celos con la destinataria de la carta, a quien por ese motivo proponía en matrimonio. Tan penetrado de soberbia y petulancia («siendo yo superior a todos cuantos Hidalgos y Petimetres pisan las calles de nuestra Ciudad»), como sobrado de falta de sensibilidad ( $\mathrm{Vm}$. sí que sabría aprovecharse de mis setecientos ducados que, en rico oro, cojo al año", p. 264), envanecido lechuguino ("verá un citoyen que acaba de hacerme el nuevo sastre que ha llegado de Madrid»), concluye rematando su escrito con otro alarde de superioridad, al despedirse como su "futuro esposo" y recalcar su condición: "El Mayorazgo. Don Vicente Pérez de Bruno Santisteban Ruiz e Ibáñez» (p. 265).

Con la de este engreído personaje terminaba la serie de misivas que requerían de casamiento a las respectivas señoritas, y se iniciaban las "Respuestas a las cartas de pretensión matrimonial»: «Primera. Respuesta de la Dama al Filósofo». En ella, dejaba bien claro la protagonista a su pretendiente que, ajena a cualquier otra disquisición, en esos puntos de matrimonio, tan trascendentes, se habría de atener a lo que dictaminasen sus padres, a quienes atribuía, por su experiencia, mayor capacidad de discernimiento que a sí misma para despachar con éxito la cuestión: "La indulgente bondad de estos Señores para con su hija es muy acreedora a que en un asunto de tanta consideración como el que Vm. me propone no deba yo mezclarme de ninguna manera» (p. 266). Y, concretamente, jugaba el papel más destacado en este campo su progenitor, «a quien juzgo bastantemente instruido para hablar con Vm. y tan apasionado por mí que no podrá negarse a ningún bien que me convenga» (p. 267) 49 .

Aparecía a continuación la "Respuesta de Don J., Padre de la Dama al Caballero» (p. 268), en donde participaba aquel al galán que su mujer y él tenían tanta confianza en la educación de su hija que la habían permitido tomar libremente resolución al respecto. Y es precisamente en este momento cuando el discurrir del relato queda salpimentado con un recurso teatral, puesto que avisa el mentado padre al candidato a la mano de su hija, a través de la misma carta que se hallaba redactando, que justo en ese instante asomaba su hija con la respuesta definitiva, y que, llevado del ansia por leer el contenido de lo que ella había escrito, se veía obligado a interrumpir su propia misiva hasta conocer el resultado de la de su hija.

49. Al igual que la de su cortejador, esta carta es la única de las cuatro réplicas que signa la localidad y el mes (aunque no el año): "Palencia y Mayo» (p. 267). Circunstancia que, por otra parte, constata la probable existencia de un error en la redacción de Marqués y Espejo; a no ser que deliberadamente hubiese dispuesto que la contestación a la expedida en Jérica, en junio, tardara once meses en ser enviada. 
Al retomar otra vez la suya, informaba indirectamente, sin descubrirlo del todo, del final feliz: "Sea para bien. Como se esperaba, y creo que nos convenga a todos. Dios haga sea así» (p. 269). En su despacho postal, incluía el susodicho progenitor la "Copia de la respuesta adjunta de la Señorita ${ }^{50}$, por medio de la cual esta, con muy discretas palabras, parecía manifestar su complacencia con la petición de su pretendiente, pero sin menoscabar un ápice la frontera del recato ni, incluso, de la ambigüedad: "Mi padre me obliga a que responda a Vm.: me manda mi madre que le diga cómo tiene mucha gana de verle; y su hija, que jamás se separa de sus órdenes, desea que Vm. les complazca; único medio para que yo pueda estimar el honor que le ha merecido siempre esta su segura servidora» (pp. 269-270).

En parecidos términos va dictada la «Respuesta de la Señora al Caballero Militar»; adscribiéndole Marqués a la dama, según se desprende del contenido de su mensaje, conocimientos históricos y mitológicos, pone nuevamente de relieve aquel las ventajas que devienen de una buena educación en la mujer, así como del cultivo de su virtud, pues saben hacerle manejar la pluma con la misma sutilidad y mesura que en el ejemplo anterior: "Mucho más [sentiría] que se ausentase Vm. sin despedirse de mí: así, no tiene que hacerlo sin decirme antes a Dios. Con esto, hasta la vista, que desearé sea para su felicidad, en que tanto se interesará siempre esta su segura servidora” (p. 271).

El colofón a esta correspondencia epistolar tiene lugar con la «Respuesta de la Señorita al Mayorazgo". Recurriendo a un agudo sentido del humor y a los juegos de palabras, que ya de entrada la sitúan en un plano intelectual superior al del infatuado sujeto que solicitó su mano, se permite aquella aconsejarle acerca de su conducta en la vida, a fin de que se comporte con más prudencia que la que en su misiva dejaba constancia. Todo ello para rechazar frontalmente la propuesta de casamiento, pero no sin que antes Marqués, echando mano de su conocimiento de la capital de Francia -en cuyo seminario estudió-, vuelva a aupar a la dama, en el terreno cultural, por encima del jactancioso heredero, mediante la advertencia que le hace aquella relativa a que las personas de las que él se rodea «atenderán más a las máximas morales que Vm. posea, que a cuantos trajes, citoyenes y vestidos inventan los maestros operistas de París, y ha producido la calle de Saint Honoré» (pp. 272-273). Y justamente, con el final de este texto, llegaba asimismo el libro a su término.

En síntesis, este conjunto de cartas originales de nuestro escritor pone de manifiesto, sin duda, su particular devoción por la figura femenina, así como

50. De ahí que en realidad esta última división del libro de Marqués contenga nueve cartas, en lugar de las ocho que podían esperarse de la suma de las cuatro solicitudes de matrimonio y de otras tantas contestaciones. 
un especial interés por su educación, personal y académica, una vía que podría terminar por liberarla, en alguna medida, de la opresiva supremacía masculina ${ }^{51}$.

Por eso, en cierto modo, constituye también este último capítulo de la Retórica epistolar un antecedente del Liceo General del Bello Sexo o de la Biblioteca selecta de las damas, ya más atrás citados.

\section{EDICIONES POSTERIORES DE LA RETÓRICA EPISTOLAR}

A esta, de 1803, primera edición de la Retórica epistolar, le sucedieron, conforme al comienzo de este estudio avanzamos, una catarata de estampaciones impresas. Sin embargo, en ninguna otra tuvo su autor la oportunidad de examinarla una vez publicada, puesto que no fue hasta 1819, un año después de morir Marqués, cuando la imprenta valenciana de Estevan llevó a cabo la segunda edición: Retórica epistolar, o arte nuevo de escribir todo género de cartas misivas y familiares, con arreglo a la nueva doctrina de los autores más célebres, así nacionales como extranjeros. Segunda edición, corregida y aumentada por su autor.

El texto contenido en esta segunda tirada, cuyo comentario es por sí mismo merecedor de un trabajo aparte, creemos que fue confeccionado, como muy tarde, entre 1814 y 1816, pues aparece en él Pedro Ceballos como primer secretario de Estado (pp. 269-270), empleo que mantuvo hasta octubre de 1816, así como el duque del Infantado como presidente del Consejo de Castilla (p. 271) ${ }^{52}$.

Por otro lado, esta impresión supone un mayor acercamiento de la obra al lector, pues las cartas francesas de la primera edición son eclipsadas ahora por una multitud de ejemplos españoles, presumiblemente coetáneos a la composición del volumen. En este aspecto, como ya dejamos dicho, las cartas de solicitud matrimonial del final de la edición de 1803 parecen constituir el antecedente de una gran parte de esta segunda versión, la cual incluye muchas situaciones cotidianas de la España de la época y confieren al título una atmósfera bastante más costumbrista 53 .

51. En este sentido no debemos obviar la circunstancia de que, en la única ocasión que en estas respuestas de las jóvenes se da voz directamente a un varón, es en la segunda de las contestaciones, donde el padre acuerda bendecir la decisión que libremente vaya a adoptar su hija para tomar matrimonio, o no.

52. Esos mismos cargos los habían ejercido anteriormente: Ceballos entre 1800-1808 e Infantado 1808-1809.

53. Tal novedad significa un paso más en la actualización de este género de literatura respecto de la primera edición de la Retórica epistolar, la cual había supuesto ya, por su parte, un avance en esa misma línea de renovación; un aspecto que contemplaba así GARCíA-GODOY: «La modernización del género epistolar español se produce, fundamentalmente, en el Siglo Ilustrado. Los tratadistas dieciochescos transforman el primigenio manual de escribientes en formularios generales de correspondencia. Los principales artífices del cambio son Antonio Marqués y Espejo y J. Antonio Begas. Ambos autores diversifican los asuntos de correspondencia, amplían el espectro social de destinatarios e introducen nuevas tipologías epistolares [...]. El moderno modo de escribir cartas supone el abandono 
Ese afán modernizador alcanzaba también a la grafía, pues se sustituye la "X» por «j”, se convierten las mayúsculas de diversos nombres comunes en minúsculas, o se eliminan aquellas "h» que, sin función alguna, conservaban internamente algunas palabras. Además, se recomendaba, para determinados casos y situaciones, la erradicación de la letra manuscrita, en beneficio de la impresa.

En sustitución del antiguo "Prefacio», se inserta ahora una introducción rotulada así: «El autor de esta obra a sus lectores, sobre la segunda edición», en la que Marqués aprovecha para felicitarse por el éxito cosechado con su libro ${ }^{54}$, y donde explica los motivos de la ampliación del mismo, puesto que había considerado "que sería de más extensión su utilidad si la perfeccionaba, añadiendo algunos modelos originales para la correspondencia epistolar» (p. 3). Aunque no sabemos si también merced a la pluma de Marqués (aunque probablemente no, puesto que eran referencias que circulaban libremente), se incorporaron en esta tirada otros datos estimados útiles, como un diccionario ortográfico o noticias de los principales caminos de España. Con lo cual las 274 páginas de la primera impresión pasaron a ser en esta 400, con al menos un $25 \%$ más de contenido en cada una de ellas.

El texto de esta segunda edición fue la base de varias otras posteriores, como, por ejemplo, de la tercera, llevada a cabo en 1824 en Gerona por Antonio Oliva, cuyo título deja consignado lo siguiente: "tercera edición, conforme a la segunda». Igualmente, en la cuarta, de 1828, fruto de la misma imprenta, una "Nota del editor" ratificaba ese extremo: "esta cuarta es rigurosa copia de la segundas ${ }^{55}$. Por su parte, Aradra (1997: 209) refiere que la Retórica epistolar

paulatino del estilo epistolar cortesano, preconizado por los secretarios de cámara» (2012: 372). A su vez, LIZARRAGA opina lo siguiente: "Aunque [la Retórica epistolar] mantiene parecida organización al Nuevo estilo y formulario de escribir cartas misivas supuso una renovación, ya que presenta modelos de autores reconocidos» (2010: 91).

54. El ejemplar del Diario Balear de 2 de setiembre de 1819, antes citado, deja sobrada constancia del fervor del público hacia esta obra: "cuya utilidad y aceptación está bastante acreditada, por el rápido despacho de la primera edición y anhelo con que se buscaba ahora, cuando aún se hallaba en la prensa" (p. 4). Por eso, no podemos estar muy de acuerdo con la consideración que realiza SEED cuando compara el tratado de Marqués con el de Gaspar de Ezpeleta y Mallol, ya antes citado, con desventaja en el ámbito de la aceptación popular para el primero: "Other less popular manuals containing model love letters include Antonio Marqués y Espejo, Retórica epistolar [...]”, siendo lo cierto, sí, que la Práctica de Secretarios de Ezpeleta había gozado de mucho éxito, pero con anterioridad a la aparición de la Retórica epistolar (1993: 765, n. 49, o 1994: 35, n. 48).

55. De esta segunda edición hemos encontrado anuncios en el Diario de Madrid de 23 de junio de 1819 (n. ${ }^{\circ}$ 174: 7): "Muy buena impresión y papel, a 10 rs. en rústica y 13 en pasta», así como en el mentado Diario Balear de 2 de setiembre de 1819 (n. ${ }^{\circ}$ 244: 3-4), que registraba su venta en la librería de Carbonell en Palma de Mallorca. En cuanto a la tercera impresión existe reseña de la misma en la Gaceta de Madrid de 17 de noviembre de 1825 (n. ${ }^{\circ}$ 139: 556b) y en la de 23 de octubre de 1827 (n. ${ }^{\circ} 130: 516 \mathrm{~b}$ ). Sin embargo, la pista del libro en los papeles periódicos no termina ahí, sino que hallamos noticias suyas a lo largo de todo el siglo XIX; por mencionar algunas, rescatamos las siguientes: El Constitucional de 27 de mayo de 1842 (n. ${ }^{\circ}$ 1171: 4b), donde se da cuenta de su venta en Barcelona, en la librería de Francisco 
gozó de numerosas ediciones en París: 1836 56 , 1840, 185757, 1865, 1866 y 1900. Asimismo, Lizama Silva $(2010)^{58}$-a la par que reconoce que la tipología de las cartas manejada por Marqués le resultó de utilidad para ordenar las de Francisco Martínez Negrete, objeto de su estudio (p. 132) - registra otra edición parisina de la Nueva retórica epistolar, esta vez en 1896 (p. 130, n. 3). Además, como al principio hemos dicho, este tratado se ha vuelto a reimprimir bien recientemente: Madrid: Marcial Pons, 2001.

\section{CONClusiones}

A lo largo del Siglo Ilustrado, un grupo cada vez mayor de personas consiguió salir del pozo oscuro de la ignorancia y del analfabetismo y fue capaz de ir acercándose, progresivamente, a la lectura de todo tipo de papeles. Además, ese gusto por el conocimiento no quedaba encerrado dentro del individuo, sino que la propia adquisición del mismo propiciaba la descripción, la argumentación o el debate entre sus congéneres. Todo ello dio lugar a nuevas fórmulas de comunicación, tanto hablada como escrita, y entre estas últimas hemos de encuadrar la de las cartas ${ }^{59}$.

Sin embargo, ese particular modo de relación había sido bastante desatendido hasta el momento en España, a cuenta precisamente de aquellas carencias de índole cultural, quedando relegado el uso de las misivas a asuntos mayoritariamente

Oliva, a 12 reales; Diario del Gobierno de la República Mexicana de 7 de agosto de 1847 (n. ${ }^{\circ}$ 147: 4d), designándolo como Nueva retórica epistolar; Diario Oficial de Avisos de Madrid de 10 de abril de 1851 (n. ${ }^{\circ}$ 101: 3c), que alude al título y, no con mucha exactitud, a su autor: "D. A. Espejo», y anota también su precio: 12 reales en pasta.

56. En 1836 se publicó en la librería de Rosa, en París, Nueva retórica epistolar [...]. Nueva edición, arreglada para el uso de las Repúblicas de América, a la cual se ha añadido una guía mercantil, en cuya portada figura como autor Marqués y Espejo, aunque solo se mencionan sus apellidos. La primera parte de este libro recoge las cartas de nuestro escritor, y se dedica en la segunda a la orientación comercial, basándose en las novedades que en este aspecto introdujo Marqués en la edición de 1819, con una sustancial ampliación respecto a lo apuntado por él, y adaptado a la realidad mexicana.

57. De este año de 1857 reseña Hidalgo dos ediciones: Novísima retórica epistolar, o arte nuevo de escribir todo género de cartas misivas y familiares por el Doctor D. Antonio Marqués y Espejo [...]. SaintCloud: imprenta de la V. de Belin, 1857; París: lib. de Garnier, hermanos, y Nueva retórica epistolar, o arte nuevo de escribir todo género de cartas misivas, familiares y de comercio, por Marqués y Espejo. Nueva edición, arreglada para el uso de las Repúblicas de América. París: imprenta de Maulde y Renou (1870, t. IV: 209b y $224 \mathrm{~b}$, respectivamente).

58. Se recogen en ese artículo de Lizama diversos comentarios sobre la correspondencia oficial en México, que cree que fueron realizados por Marqués (p. 131), aunque corresponden a ediciones de su obra posteriores a su muerte; por eso, suponemos que tales añadidos son de mano de un tercero, y debían de ir dirigidos, como su título avanza, a los países hispanoparlantes.

59. RUEDA afirma: "Los libros voluminosos cansan e importunan; la carta, que adopta el ropaje de la conversación invocando naturalidad y falta de afectación, se emplea con preferencia creciente para la exposición de ideas» (2015: 15). 
oficiales, y su redacción confiada a la pluma de gente experta en la materia; por lo cual quedaban las cartas personales generalmente en manos de la más absoluta improvisación por parte de los interesados, ayunos de un método por el que guiarse.

Diversos autores, especialmente Juan Antonio D. y Begas, habían publicado en la segunda mitad del XVIII algún que otro tratado con el fin de paliar, al menos parcialmente, dicha laguna, y de satisfacer así las exigencias de una sociedad más urbana y burguesa, culta y dinámica. Pero no será hasta la aparición en las prensas de la Rétorica epistolar cuando la cuestión dé un salto cualitativo; porque el libro de Marqués no se limitaba a plasmar una serie de textos con el objeto de que el remitente intentara encajar en su carta el contenido de aquellos modelos, sino que, al amparo de su fuente principal: Le secrétaire parfait, ou modéles de lettres sur différents sujets, de Philipon, además de facilitar un variopinto abanico de cartas de contrastada calidad literaria -que Marqués se aprestó a acercar lo más posible a la realidad hispana-, se aplicó en facilitar las normas principales que debían regir cada tipo de misiva.

Y no solo eso, sino, que merced a su experimentada prudencia y profundo conocimiento del alma humana, pudo nuestro presbítero proveer al lector de los consejos necesarios y de los tonos justos en los que debía moverse al componer su contenido, mucho más sensible que el de los libros, destinados a un incógnito receptor, no como aquí, en donde el destinatario bien podía ser un amigo, susceptible de ser molestado de no calibrarse bien las palabras, un superior al que desagradara la opinión vertida, etc.

De otra parte, la disposición de Marqués de volcarse decididamente en la búsqueda de la prosperidad de la mujer, y en todo momento atento a ensalzar los beneficios de su educación y de su adiestramiento en el sendero de la virtud -en lo cual quizá influyó su condición de capellán en una institución de acogida de féminas de infausto pasado-, queda reflejada, de manera principal, en la secuencia de cartas, esta vez creemos que de su propia y original cosecha, con que puso fin a su manual. Allí, dejó manifiesta constancia de que una dama ilustrada en nada debía envidiar a los hombres; sino que, antes al contrario, podía superarlos en cuanto a puntos de sensatez y cordura, valentía y hasta de sutilidad a la hora de sostener la pluma, pasos indispensables, junto con algunos otros, en el camino que habría de conducirle a la liberación de las muchas dependencias que mantenía respecto del varón.

Finalmente, hemos de señalar que la primera edición de la Retórica epistolar, en cierto modo pionera en su campo, resultó posteriormente modernizada en mucha medida en la segunda, de 1819 (que ya no alcanzó a ver nuestro escritor, fallecido el año antes), puesto que, sin perjuicio de mantener las cartas insertadas en la primera, apareció plagada de novedades y de elementos de actualidad extraídos de la realidad inmediata, que propiciaban una mayor inmersión en las costumbres y en la vida social de su tiempo. 


\section{Bibliografía}

Álvarez De Miranda, Pedro. "Hacia una historia de los diccionarios españoles en la Edad Moderna». Bulletin Hispanique, 1995, t. 97, n. ${ }^{\circ}$ 1, pp. 187-200.

Álvarez De Miranda, Pedro. «El viage de un filósofo a Selenópolis (1804) y su fuente francesa». En Lerner, Isaías; Nival, Robert y Alonso, Alejandro (eds.). Actas del XIV Congreso de la Asociación Internacional de Hispanistas. Newark, Delaware: Juan de la Cuesta, 2001, t. III, pp. 43-51.

ARADRA SÁNChEZ, Rosa María. De la retórica a la teoría de la literatura (siglos XVIII y XIX). Murcia: Universidad de Murcia, 1997.

ARADRa SÁNCHEZ, Rosa María. «Sobre la presencia francesa en las retóricas españolas del siglo XVIIIm. En BOIXERAU, Mercedes y Desné, Roland (dirs.). Recepción de autores franceses de la época clásica en los siglos XVIII y XIX en España y en el extranjero. Madrid: UNED, 2001, pp. 59-70.

ARADRA SÁNCHEZ, Rosa María. «Reescritura y valor literario: fuentes y letras europeas en la teoría literaria española del siglo XIX”. Alicante: Biblioteca Virtual Miguel de Cervantes, 2010, pp. 135-146.

ATAIDE y PORTUGal, Enrique. Colección de filósofos moralistas antiguos. Madrid: Aznar, 1803.

Cantos Casenave, Marieta. "Cartas y epistolarios. Cultura de la correspondencia misiva y práctica editorial. Presentación de la sección monográfica». Cuadernos de Ilustración y Romanticismo, 2015, n. ${ }^{\circ}$ 21, pp. 1-6.

CAstillo GómeZ, Antonio. "De la tipografía al manuscrito. Culturas epistolares en la España del siglo XVIII». En Castillo Gómez, Antonio (dir.). Culturas del escrito en el mundo occidental. Del Renacimiento a la contemporaneidad. Madrid: Casa de Velázquez, 2015, pp. 81-98.

D. Y BEGAS, Juan Antonio. Nuevo estilo y formulario de escribir cartas misivas [...]. Madrid: José Doblado, 1774.

Doctor Thebussem [Mariano Pardo de Figueroa]. «Fórmulas». La Ilustración Hispano-americana de 6 de setiembre de 1891, n. ${ }^{\circ}$ 566, pp. 566-57.

EARle, Rebeca. "Letters and Love in Colonial Spanish America». The Americas, jul. 2005, vol. 62, n. ${ }^{\circ} 1$, pp. $17-46$.

FeIjOO, fray Benito Jerónimo. Teatro crítico universal, o discursos varios en todo género de materias para desengaño de errores comunes. Madrid: Antonio Marín, 1765, t. VII. 1. ${ }^{a}$ edición: 1736.

García Malo, Ignacio. "Prólogo del traductor». En Richardson, Samuel. Pamela Andrews o la virtud recompensada [...]. Madrid: Antonio Espinosa, 1794-95. Citamos por la segunda edición: Pamela Andrews o la virtud premiada [...]. Madrid: Imprenta Real 1799, t. I.

García-Godoy, María Teresa. "Una tradición textual en el primer español moderno: los tratados de misivas». Études Romanes de Brno, 2012, n. ${ }^{\circ} 33.1$, pp. 357-376.

Hidalgo, Dionisio. Diccionario general de bibliografía española. Madrid: Imprenta de J. Limia y G. Urosa, 1870, t. IV.

Levesque, Pierre Charles. Sentences de Théognis, de Phocylide, de Pythagore, et des sages de la Grece, recueilles et traduites. En Collection des moralistes anciens. Dédiée au Roi. París: Chez Didot l'Aîne et de Bure l'Aîne, 1783, pp. 199-219. 
LA RETÓRICA EPISTOLAR (1803), DE ANTONIO MARQUÉS Y ESPEJO, COMO MÉTODO PARA FACILITAR...

LizAma SiLva, Gladys. «Correspondencia y vida cotidiana. Francisco Martínez Negrete Alba, Guadalajara, México, 1903-1904». Jahrbuch für Geschichte Lateinamerikas-Anuario de Historia de América Latina, 2010, n. ${ }^{\circ}$ 47, pp. 127-153.

LIZARRAGA, Juan Manuel. «Una colección de esquelas impresas del siglo XVIII: la correspondencia del I Duque de San Carlos». Pecia Complutense, 2010, n. ${ }^{\circ} 12$, pp. 82-107.

MARQUÉS Y ESPEJO, Antonio. El perfecto orador, o principios de elocuencia sagrada [...]. Valladolid: Viuda e Hijos de Santander, 1793.

Marqués y EsPejo, Antonio. Desahogos líricos de Celio, dedicados al dios Apolo. Madrid: Repullés, 1802.

MARQUÉS Y ESPEJO, Antonio. Retórica epistolar, o arte nuevo de escribir todo género de cartas misivas y familiares; con ejemplos de los autores más célebres extranjeros y nacionales. Madrid: Cruzado, 1803.

MARQuÉs y ESPEjo, Antonio. Viaje de un filósofo a Selenópolis. Madrid: Gómez Fuentenebro y Compañía, 1804.

MARQuÉS y ESPEJO, Antonio. Almanak literario, manual utilísimo para los comerciantes de libros y apasionados a la literatura [...], t. I. Imprenta de Repullés, 1804.

MARQués y EsPejo, Antonio. Liceo General del Bello Sexo. AHN, Consejos, 5566-59 (1804).

MARQUÉS Y ESPEJO, Antonio. Miss Clara Harlowe, drama en tres actos y en verso: suplemento a la historia inglesa del mismo título. Madrid: Imprenta de la Viuda de Ibarra, 1804.

MaYANS y SisCar, Gregorio. Cartas de D. Nicolás Antonio y de D. Antonio de Solís. Añádese una de D. Cristóbal Crespi de Valdaura. Lyon: Deville Hermanos, 1733.

MAYANS Y SISCAR, Gregorio. Cartas morales, militares, civiles y literarias de varios autores españoles. Madrid: Juan de Zúñiga, 1734.

MORÁN OrTI, Manuel. «La imprenta y librería "Qué fue de Fuentenebro”: un modelo empresarial y un programa editorial a finales del Antiguo Régimen". Ayer. La formación de los Estados-naciones americanos (1808-1830), 2009.2, n. ${ }^{\circ}$ 74, pp. 165-190.

Philipon de la MAdelaine, Louis. Modéles de lettres sur différents sujets. Bouillon: Chez Jean Brasseur, 1761.

Philipon De la MADELAINe, Louis. Le secrétaire parfait, ou modéles de lettres sur différents sujets, corrigée et augmentée. Venise: Chez Thomas Bettinelli, 1786.

RodríGuEz Morín, Felipe. "Aproximación biográfica y literaria a Antonio Marqués y Espejo (1762-1818)». Cuadernos de Estudios del Siglo XVIII, 2017, n. ${ }^{\circ} 27$, pp. 285-322 (DOI: https://doi.org/10.17811/cesxviii.27.2017.285-322).

RodríGuez Morín, Felipe. "El Liceo General del Bello Sexo». El Argonauta Español, 2018, n. ${ }^{\circ}$ 15 (DOI: 10.4000/argonauta.2822).

RuEDA, Ana. Cartas sin lacrar. La novela epistolar y la España Ilustrada. 1789-1840. Madrid: Iberoamericana-Vervuert, 2001.

RuEDA, Ana. "Cartas y cartapacios: la crítica literaria del XVIII ante la "vana erudición" del coleccionismo". Cuadernos de Ilustración y Romanticismo, 2015, n. ${ }^{\circ}$ 21, pp. 11-23.

SÁnchez EsPinOSA, Gabriel. "Madame de Sévigné y la carta familiar en España durante el siglo XVIII». En BoIXERAU, Mercedes y Desné, Roland (dirs.). Recepción de autores franceses de la época clásica en los siglos XVIII y XIX en España y en el extranjero. Madrid: UNED, 2001, pp. 111-123.

SEED, Patricia. «Narratives of Don Juan: The Languaje of Seduction in Seventeenth-Century Hispanic Literature and Society". Journal of Social History, 1993, vol. 26, n. ${ }^{\circ} 4$, Summer, pp. $745-768$. 
LA RETÓRICA EPISTOLAR (1803), DE ANTONIO MARQUÉS Y ESPEJO, COMO MÉTODO PARA FACILITAR...

SEED, Patricia. «Narrativa de Don Juan: a linguagem de sedução na literatura e na sociedade espanhola do século dezessete». Cuadernos PAGU, 1994, n. ${ }^{\circ}$ 2, pp. 7-45.

Sos, Melchor de. Arte epistolar, o reglas teórico-prácticas para escribir cartas [...]. Barcelona: Tomás Gorchs, 1819.

Trojani, Mary Cécile. "Amitié et écriture épistolaire en Espagne au XVIII siècle». 2012, n. ${ }^{\circ}$ 12, vol. 3: L'expression de l'intériorité : vivre et dire l'intime à l'époque moderne. Centre Interlangues, s. n.

VilleneueVE De Listonay, Daniel Jost de. Le voyageur philosophe dans un pais inconnu aux habitants de la terre. Amsterdam, 1761. 